\title{
Effects of Chain Transfer Agent and Temperature on Branching and $\beta$-Scission in Radical Polymerization of 2-Ethylhexyl Acrylate
}

Jean-Baptiste Lena, ${ }^{a}$ Michaël Deschamps, ${ }^{b}$ Natasha F. Sciortino, ${ }^{c}$ Sarah L. Masters, ${ }^{a}$ Marie A. Squire, ${ }^{a}$ Gregory T. Russell ${ }^{a, *}$

a School of Physical and Chemical Sciences, University of Canterbury, Private Bag 4800, Christchurch, New Zealand

${ }^{b}$ CNRS, CEMHTI UPR3079, Univ. Orléans, F-45071 Orléans, France

' School of Chemistry, The University of Sydney, Sydney, New South Wales 2006, Australia

* Corresponding author. Tel. +64 3369 5129. Email: greg.russell@canterbury.ac.nz

\section{Abstract}

Poly(2-ethylhexyl acrylate) was synthesized by conventional radical bulk polymerization both with and without 1-dodecane thiol as chain transfer agent (CTA) at temperatures from 4 to $140{ }^{\circ} \mathrm{C}$. Electrospray-ionization mass spectrometry was used to analyze the polymer. This revealed the occurrence of significant $\beta$-scission at high temperature and confirmed the presence of CTA-capped polymers at all temperatures, as well as combination products from 4 to $65{ }^{\circ} \mathrm{C}$. Subsequent ${ }^{13} \mathrm{C}$ melt-state NMR analysis allowed quantification of branching and $\beta$-scission. Both are reduced when CTA is present, consistent with a "patching" effect. As expected, the amounts of $\beta$-scission and branching increase with synthesis temperature, although $\beta$-scission dominates at the highest temperature. The backbiting rate coefficient of 2-ethylhexyl acrylate was determined from NMR results, taking $\beta$-scission into account for the first time. Remarkable agreement with literature $k_{\mathrm{bb}}$ values was obtained, especially for activation energy. This strongly suggests family-type behavior for acrylate $k_{\mathrm{bb}}$.
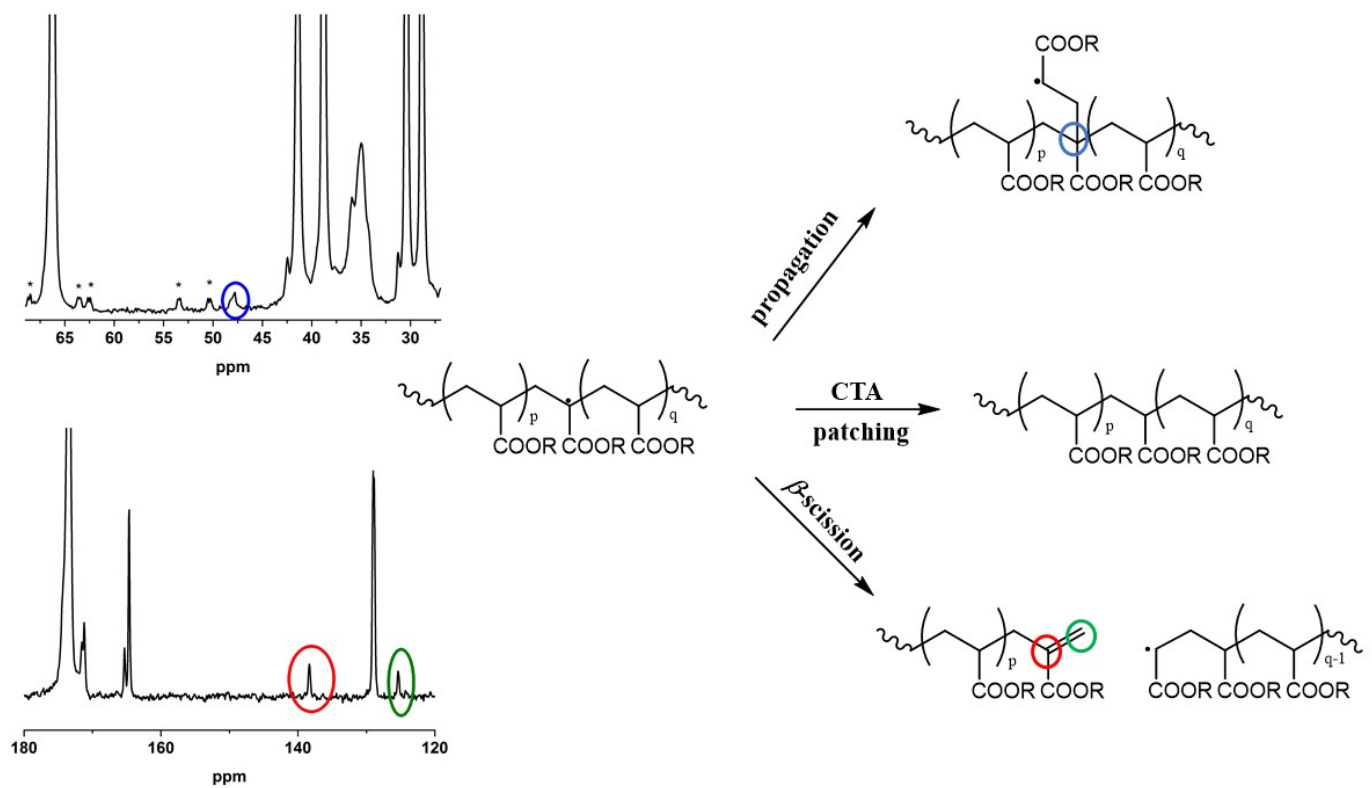


\section{Keywords}

Poly(2-ethylhexyl acrylate); NMR; electrospray ionization (ESI)-mass spectrometry; branching; $\beta$-scission.

\section{Table of Contents}

Poly(2-ethylhexyl acrylate) was synthesized from 4 to $140{ }^{\circ} \mathrm{C}$ and characterized by electrospray-ionization mass spectrometry and ${ }^{13} \mathrm{C}$ melt-state NMR spectroscopy. The percentages of branching points and unsaturated terminal double bonds were determined, and thus the backbiting rate coefficient was estimated.
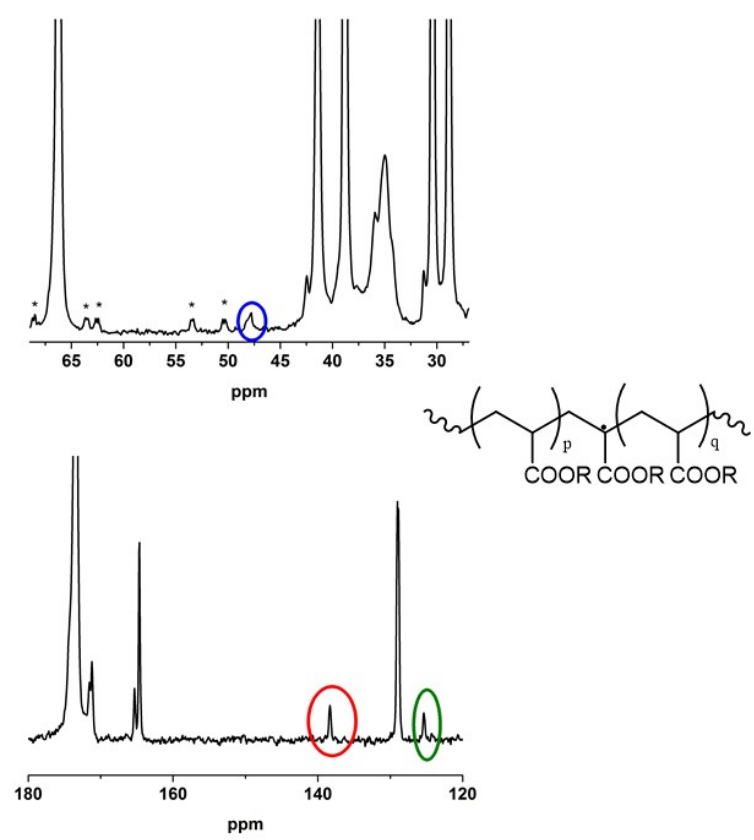
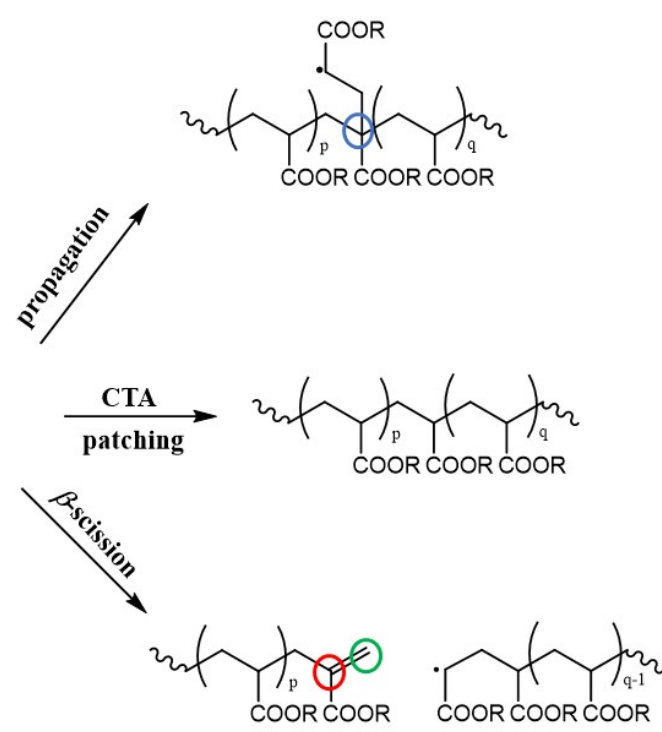

\section{Introduction}

Poly(2-ethylhexyl acrylate) (P2EHA) is a hydrophobic polymer. The long ester sidegroup strongly influences properties such as viscosity and glass transition temperature, $T_{\mathrm{g}}$, which is far below room temperature. A high number of applications of P2EHA have been reported in the literature. The main ones are waterborne coatings, ${ }^{[1]}$ pressure sensitive adhesives ${ }^{[2]}-$ thanks to its low $T_{\mathrm{g}}$ - and nanocomposites. ${ }^{[3]}$ When produced by radical polymerization, P2EHA is branched, ${ }^{[4-6]}$ indeed both long- and short-chain branching (LCB and SCB

respectively) have been detected in P2EHA. ${ }^{[6]}$ In terms of kinetics, SCB arises from intramolecular transfer (near the chain end), also known as backbiting, of rate coefficient $k_{\mathrm{bb}}$, while LCB often arises either from random intramolecular transfer or from intermolecular transfer to polymer. All three of these reactions transform a secondary propagating radical (SPR) into a mid-chain radical (MCR). MCRs can undergo several 
reactions, including: $\beta$-scission, leading to an unsaturated, unbranched dead chain and an SPR; propagation, with a rate coefficient, $k_{\mathrm{p}}{ }^{\mathrm{t}}$, that is much lower than the SPR propagation rate coefficient, $k_{\mathrm{p}}$; and termination. Note that both propagation and termination by combination lead to branched species. When a chain transfer agent (CTA) is present among the reactants, atom transfer from CTA to an MCR may occur, leading to observation of unbranched species. ${ }^{[7-9]}$ This is called the "patching effect". All these reactions are presented in Scheme 1.

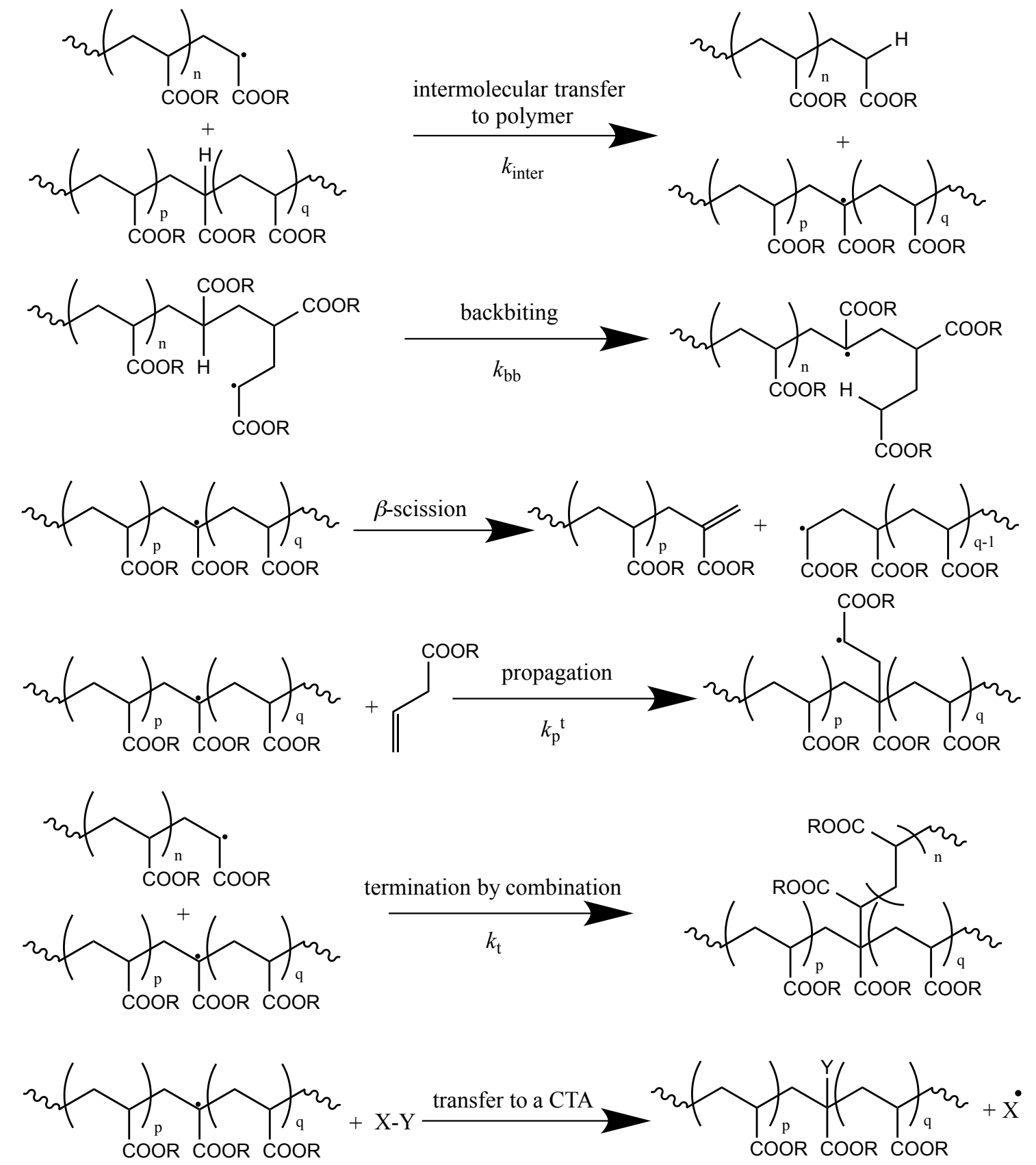

Scheme 1: Various pathways for obtaining and consuming MCRs. 
It is important to note that there are even more possible reactions than those shown in Scheme 1. For example, LCB may also arise from MCR addtion to macromonomer, ${ }^{[10]}$ as formed either by $\beta$-scission (see Scheme 1) or termination by disproportionation (also not in Scheme 1, as acrylates are believed to undergo primarily combination). Furthermore, a study on P2EHA by electrospray-ionization (ESI) MS has demonstrated that the radical on an MCR can migrate along the chain, which could lead either to different branch lengths (if propagation and termination occur) or different sizes of unsaturated dead chain, due to $\beta$ scission. ${ }^{[11]}$ For a more detailled overview on this melting pot of reactions, the reader is referred to a recent review on "Radical polymerization of acrylic monomers". ${ }^{12]}$

Of course it is well known that branching influences the properties of a polymer: short branches primarily influence physical properties such as density, melting point and glass transition temperature, while long branches primarily influence rheological properties. ${ }^{[13]}$

${ }^{13} \mathrm{C}$ NMR spectroscopy is by far the superior method for quantification of branching in polymers. At a branching point there is a quaternary carbon, denoted $C_{q}$, that exhibits a signal around $48 \mathrm{ppm}^{[4-6]}$ The average degree of branching, $D B$ - i.e. the number of branches per monomer unit - is calculated by comparing the integral of the $C_{q}$ signal with that of a carbon whose characteristics remain unchanged over the polymerization process. Both resolution and sensitivity are required for reliable quantification of the branching. Various NMR methods - solid-state, solution-state and melt-state - have been tested for the study of branching. ${ }^{[14]}$ Melt-state appears to provide the highest resolution. ${ }^{[14]}$ For optimal analyses, melt-state ${ }^{13} \mathrm{C}$ NMR spectroscopy is best performed at $T_{\mathrm{g}}+150{ }^{\circ} \mathrm{C} .{ }^{[14]}$ As the $T_{\mathrm{g}}$ of P2EHA is quite low and P2EHA is expected to degrade only above $300{ }^{\circ} \mathrm{C}$, this method can be applied to quantify the branching in P2EHA. ${ }^{[14]}$

Both ${ }^{13} \mathrm{C}$ solution- and melt-state NMR spectroscopy have previously been used to quantify the branching in P2EHA synthesized in solution and emulsion. ${ }^{[4-6,14]}$ Similar studies were carried out for other poly(alkyl acrylate)s ${ }^{[6,8,15-18]}$ and poly(acrylic acid) (PAA). ${ }^{[9,19-21]}$ In 2001, Heatley et al. used ${ }^{13} \mathrm{C}$ solution-state NMR spectroscopy to quantify the branching in P2EHA produced in solution. Their results indicated that transfer to polymer: (i) Increases with conversion, which would be expected due to rising [P] (if the transfer is intermolecular 
in nature) and/or decreasing [M] (if intramolecular); (ii) Increases as the initial monomer concentration decreases, which is most likely explained by a decreasing frequency of SPR propagation. Another effect they observed was (iii) $D B$ of P2EHA is higher than $D B$ of poly $(n-$ butyl acrylate) (PnBA) prepared under the same conditions. They concluded that "changes in $k_{\mathrm{bb}} / k_{\mathrm{p}}$ must account for the observed differences in the extent of chain transfer to polymer", ${ }^{[4]}$ i.e., that this rate coefficient ratio must be larger for $2 \mathrm{EHA}$. Certainly this is in accord with the recent results of Kattner and Buback, who found that the fraction of MCR sites increases as side-group length increases. ${ }^{[22]}$ One would expect this to result from higher preexponential factor rather than altered activation energy. ${ }^{[4,22]}$

Theoretically, branches could be formed in 2EHA polymerization on the ester side group as it contains a tertiary $\mathrm{CH}$, which is a potential site for hydrogen abstraction. This would lead to a quaternary carbon whose ${ }^{13} \mathrm{C}$ NMR signal is predicted to be $\sim 45 \mathrm{ppm}$. However, this signal has never been observed. Furthermore, it is now widely accepted that transfer to polymer in acrylates occurs at tertiary $\mathrm{CH}$ sites in the polymer backbone, as these are "activated" by the adjacent carbonyl group.

In 2001, Plessis et al. demonstrated that in emulsion polymerization of $2 \mathrm{EHA}, D B$ increases with the initiator concentration and decreases with the monomer concentration, which suggests that most branches are formed by backbiting. ${ }^{[5]}$ Even if intramolecular transfer was dominant, the occurrence of some LCB due to intermolecular transfer was also suggested by gel formation. ${ }^{[5]}$ In 2004, Sato et al. studied the polymerization in benzene of 2EHA and tertbutyl acrylate (tBA). Using electron paramagnetic resonance (EPR) spectroscopy, the presence of both LCB and SCB was demonstrated. Also, the MCR concentration in 2EHA polymerization was shown to be higher than that in tBA polymerization, ${ }^{[6]}$ and their studies of branching by ${ }^{13} \mathrm{C}$ NMR spectroscopy confirmed a higher $D B$ for P2EHA than for PtBA. However, they suggested that this could be due to a faster termination process in the case of $t B A$ polymerization. ${ }^{1} \mathrm{H}$ NMR spectra showed the presence of unsaturated groups, providing evidence for the occurrence of $\beta$-scission. They showed that if the polymerization is carried out at $25^{\circ} \mathrm{C}$, the presence of MCRs is important, but neither branching nor $\beta$ scission could be detected by NMR spectroscopy. ${ }^{[6]}$ This suggests that both fragmentation and propagation of MCRs are negligible at such a low temperature. 
Studies on PAA and PnBA show that $D B$ increases with the temperature, which is likely due to an increase in $k_{\mathrm{bb}} / k_{\mathrm{p}}$ due to backbiting having a higher activaiton energy. Furthermore, $D B$ is considerably reduced by the presence of a CTA among the reactants. ${ }^{[23]}$ Two explanations were suggested: either a reduction in backbiting as the polymerization occurs for a shorter time, or transfer from a CTA to the MCR, known as the "patching effect". [7-9]

The development of ESI-MS has enabled determination of the product spectrum of a polymer sample and its changes within the chain length distribution. ${ }^{[23,24]}$ Polymer chains can be sorted precisely according to their end groups and chain length. The influence of temperature and of CTA concentration on the structure of PnBA has been studied by ESIMS. ${ }^{[25,26]}$ The amount of $\beta$-scission increased with temperature and decreased with CTA concentration. However, it is challenging to obtain consistent ionization of different macromolecules within a sample: it is well known that different end-groups ${ }^{[27]}$ or molar masses ${ }^{[28]}$ can affect the ionization efficiency. This limits the accuracy of the average molar mass values and molar mass distributions determined by MS. In 2013, Vandenbergh et al. detected the $\beta$-scission products (without specific quantification) of P2EHA synthesized by controlled radical polymerization as well as the chain length selectivity. ${ }^{[11]}$

LCB was detected in P2EHA produced by PLP using multiple-detection size-exclusion chromatography (SEC), even at low temperature (down to $\left.-34^{\circ} \mathrm{C}\right)^{[29]}$ and at low conversion. ${ }^{[30]}$ The local dispersities, $\bigoplus\left(V_{h}\right)$, obtained can reach values close to 2 . This means that the error in molar mass determination using SEC can reach $100 \% .{ }^{[29-31]}$ The occurrence of $L C B$, leading to inaccurate molar mass determination by SEC, is more important for P2EHA than for acrylates with shorter side groups, like PnBA and poly(methyl acrylate). It was suggested that the bulky ester group of 2EHA does not favour the formation of a sixmembered ring, and thus more random intramolecular transfer would occur. ${ }^{[31]}$ One consequence of the presence of LCB is inaccurate $k_{p}$ determination using the technique of pulsed laser polymerization coupled with SEC (PLP SEC). Even though there have been several attempts to determine $k_{\mathrm{p}}$ in 2EHA polymerization, it is suspected that the obtained values suffer from relatively low accuracy due to LCB. For example, the error in PLP-SEC values for P2EHA was estimated to be between $30-100 \%$ for $-34{ }^{\circ} \mathrm{C}<\theta<22^{\circ} \mathrm{C}$ [29] 
Although - as outlined above - there is a reasonable sized body of work on branching in acrylates, including some attention to 2EHA in particular, there are several motivations for the present investigation: (1) As is evident, there is some conflict in the literature: whether branching is present in P2EHA synthesized at low temperature, how the DB of P2EHA compares with that for other acrylates (with the different literature trends giving rise to contrasting mechanistic explanations), and so on; (2) Literature studies have not always been as systematic as one would prefer; (3) Advances in NMR instruments and in understanding of how best to use NMR for branching investigations mean that more accurate data may now be obtained; and (4) We would like to build on our preceding study

of $\mathrm{PAA},{ }^{[9]}$ in particular with a view to establishng the effect of sidegroup size on $D B$. For these reasons, the aim of this work was to synthesize P2EHA in bulk at various temperatures (from $4{ }^{\circ} \mathrm{C}$ to $140{ }^{\circ} \mathrm{C}$ ) both with and without CTA. The end-groups of CTA-containing P2EHA were characterized using ESI-MS, and the $D B$ as well as the degree of $\beta$-scission, $D \beta S$, of all P2EHA samples were determined by ${ }^{13} \mathrm{C}$ melt-state NMR spectroscopy, where $D \beta S$ is defined here in analogy with $D B$, i.e., it is the number of unsaturated end groups produced by $\beta$ scission per monomer unit.

\section{Materials and Methods}

\subsection{Materials}

2,2'-azobisisobutyronitrile (AIBN) was purchased from Akzo Nobel. Aluminium oxide, activated basic, Brockmann I, standard grade was provided by Sigma-Aldrich. Iron(II) sulfate 7-hydrate was purchased from BDH laboratories. Tert-butyl hydroperoxide ( $t$-BuOOH) (5.5 $\mathrm{mol} \mathrm{L}^{-1}$ in decane) was purchased from Fluka. 1-dodecanethiol ( $\geq 98 \%$ ) and 2-ethylhexyl acrylate (2EHA) (98\%) were purchased from Aldrich Chemistry. Chloroform- $d_{3}(\geq 99.75 \%)$ was provided by Acros Organics. Acetonitrile and methanoic acid (analytical grade) were provided by Fluka. Dichloromethane (DCM; HPLC grade) and methanol (MeOH; HPLC grade) were passed through a solvent purification system. ${ }^{[32]}$

AIBN was recrystallized twice in methanol. 2EHA was passed through a column of activated basic alumina to remove the inhibitor. 1-dodecanethiol, iron(II) sulfate and $t$ - $\mathrm{BuOOH}$ were used as received. 


\subsection{Synthesis of P2EHA}

\section{Synthesis with a thermal initiator}

Into a Schlenk round bottom flask, $6.5 \mathrm{~mL}$ of $2 \mathrm{EHA}\left(3.1 \times 10^{-2} \mathrm{~mol}\right), 0$ or $0.62 \mathrm{~mL}$ of 1 dodecanethiol ( 0 or $2.6 \times 10^{-3} \mathrm{~mol}$ ) and $5.5 \mathrm{mg}$ of AIBN $\left(3.3 \times 10^{-5} \mathrm{~mol}\right)$ were added. The Schlenk round bottom flask was degassed by bubbling nitrogen through the solution for 30 min. The mixture was left under stirring at $65^{\circ} \mathrm{C}, 100{ }^{\circ} \mathrm{C}$ or $140{ }^{\circ} \mathrm{C}$ for $24 \mathrm{hr}, 40 \mathrm{~min}$ and 20 min respectively. After these reactions times, the samples were quenched in ice water. Excess unreacted thiol compound and residual monomer were removed under vacuum on a Schlenk line at ambient temperature for 5 days. Conversion was determined by gravimetry and ${ }^{13} \mathrm{C}$ NMR spectroscopy. Detailed results are in Table S1.

\section{Synthesis with a redox initiator}

Into a Schlenk round bottom flask, $3.5 \mathrm{~g}$ of $2 \mathrm{EHA}\left(1.9 \times 10^{-2} \mathrm{~mol}\right), 0$ or $417 \mu \mathrm{L}$ of 1 dodecanethiol $\left(1.7 \times 10^{-3} \mathrm{~mol}\right)$ were added. The Schlenk round bottom flask was degassed by bubbling nitrogen through the solution for $30 \mathrm{~min}$, then $2.22 \mathrm{~g}$ of iron(II) sulfate $(7.9 \times$ $\left.10^{-3} \mathrm{~mol}\right)$ and $200 \mu \mathrm{L}$ of $t-\mathrm{BuOOH}\left(2.1 \times 10^{-3} \mathrm{~mol}\right)$ were added. Samples were then left under stirring at room temperature for 24 hours, or in the fridge at $4{ }^{\circ} \mathrm{C}$ for 4 days or 9 days for synthesis with and without CTA respectively. The samples were quenched by opening the flask. Excess unreacted thiol compound and residual monomer were removed under vacuum on a Schlenk line at ambient temperature for 5 days. Conversions were measured by ${ }^{1} \mathrm{H}$ solution-state NMR spectroscopy. Details about the conversion measurement are given in the Supporting Information (Figures S1 to S3).

1-dodecanethiol (DDM) was chosen as CTA because it is known to function well for polymerization of alkyl (meth)acrylates in bulk. ${ }^{[33,34]}$

Table 1 summarises all reactions conditions together with resulting conversion and numberaverage degree of polymerization, $D P_{\mathrm{n}}$. The latter were determined by comparing the (NMR) signals of terminal $\mathrm{CH}_{2}$ to main chain $\mathrm{CH}$. End groups corresponding to dead chains formed by combination were too low to detect by ${ }^{13} \mathrm{C}$ NMR spectroscopy. Consequently, the number of end groups is underestimated and so $D P_{\mathrm{n}}$ values are overestimated. Of course 
this analysis is only possible where chain lengths are relatively short, as promoted by higher temperature and the presence of CTA.

Table 1: Reactants, temperatures, conversions and polymer sizes of 2EHA polymerizations.

\begin{tabular}{cccccc}
\hline Sample & Initiator/CTA & $\begin{array}{c}\text { Reaction } \\
\text { temperature }\end{array}$ & $\begin{array}{c}\text { Reaction } \\
\text { time }\end{array}$ & $\begin{array}{c}\text { Final } \\
\text { conversion }\end{array}$ & $\begin{array}{c}\boldsymbol{D P}_{\mathrm{n}} \text { (with } \\
\text { error*) }\end{array}$ \\
\hline P2EHA-1 & AlBN/DDM & $140{ }^{\circ} \mathrm{C}$ & $20 \mathrm{~min}$ & $81 \%$ & $8.1 \pm 1.5 \%$ \\
P2EHA-2 & AlBN/none & $140{ }^{\circ} \mathrm{C}$ & $20 \mathrm{~min}$ & $89 \%$ & $33.7 \pm 10 \%$ \\
P2EHA-3 & AlBN/DDM & $100{ }^{\circ} \mathrm{C}$ & $40 \mathrm{~min}$ & $79 \%$ & $7.4 \pm 16 \%$ \\
P2EHA-4 & AIBN/none & $100{ }^{\circ} \mathrm{C}$ & $40 \mathrm{~min}$ & $87 \%$ & $26.2 \pm 12 \%$ \\
P2EHA-5 & AIBN/DDM & $65{ }^{\circ} \mathrm{C}$ & $24 \mathrm{~h}$ & $59 \%$ & $14.6 \pm 9.2 \%$ \\
P2EHA-6 & AIBN/none & $65{ }^{\circ} \mathrm{C}$ & $24 \mathrm{~h}$ & $93 \%$ & - \\
P2EHA-7 & $\mathrm{Fe}^{2+}+t$-BuOOH/DDM & $25{ }^{\circ} \mathrm{C}$ & $24 \mathrm{~h}$ & $87 \%$ & $14.5 \pm 5.6 \%$ \\
P2EHA-8 & $\mathrm{Fe}^{2+}+t$-BuOOH/none & $25{ }^{\circ} \mathrm{C}$ & $24 \mathrm{~h}$ & $80 \%$ & - \\
P2EHA-9 & $\mathrm{Fe}^{2+}+t$-BuOOH/DDM & $4{ }^{\circ} \mathrm{C}$ & 4 days & $91 \%$ & - \\
P2EHA-10 & $\mathrm{Fe}^{2+}+t$-BuOOH/none & $4{ }^{\circ} \mathrm{C}$ & 9 days & $70 \%$ & - \\
\hline
\end{tabular}

* Obtained by considering the error in the area of each NMR signal used to determine $D P_{\mathrm{n}}$.

\subsection{Electrospray Ionization-Mass Spectrometry}

The samples for ESI-MS analysis were prepared as follows: $1 \mathrm{mg}$ of P2EHA was dissolved in 1 $\mathrm{mL}$ of $\mathrm{DCM} / \mathrm{MeOH}(7 / 3 \mathrm{v} / \mathrm{v})$. The samples were injected into a Thermo Fisher Scientific Dionex UltiMate 3000 liquid chromatography (LC) system (without a column) comprised of an Ultimate 3000 RS Pump, 3000 RS Autosampler, 3000 RS Column Compartment and a 3000 Diode Array Detector. The LC system was attached to a Bruker maXis 3G Ultra High Resolution -Qq- Time of Flight tandem mass spectrometer (Bruker Daltonik GmbH, Bremen, Germany). The isocratic mobile phase comprised $0.1 \%(\mathrm{v} / \mathrm{v})$ formic acid and $50 \%(\mathrm{v} / \mathrm{v})$ acetonitrile in water at a flow rate of $200 \mu \mathrm{L} \mathrm{min}{ }^{-1}$. Ions were generated by electrospray ionization (ESI) and cleansed of solvent by a nitrogen flow of $8.0 \mathrm{~L} \mathrm{~min}^{-1}$ with temperature of $200{ }^{\circ} \mathrm{C}$, nebulizer at 1 bar, end plate offset at $500 \mathrm{~V}$, capillary voltage at $4000 \mathrm{~V}$; analysis was in positive-ion mode. The intensity of positive ions was recorded in the range of 100-3000 
$\mathrm{m} / \mathrm{z}$, at a rate of $2 \mathrm{~s}^{-1}$ and analysed using Bruker Compass HyStar $3.2-\mathrm{SR} 2$ (Build 44). ESI-L Low Concentration Tuning Mix (Agilent Technologies) was injected after each sample as a calibrant.

\subsection{Thermal Analyses}

\section{Differential scanning calorimetry (DSC)}

P2EHAs were analysed with a Mettler 823E DSC instrument. Samples were accurately weighed into $40 \mu \mathrm{L}$ aluminium crucibles and crimped shut with a pierced lid. A similar empty crucible with a crimped pierced lid was used as a reference. The samples were cycled in a heat-cool-heat sequence between $-150^{\circ} \mathrm{C}$ and $150^{\circ} \mathrm{C}$ at rate of $10^{\circ} \mathrm{C} \mathrm{min}-1$ under a high purity nitrogen gas flow of $50 \mathrm{~mL} \mathrm{~min}^{-1}$. Some sample measurements included an additional 'cooling-heating' step. The first heating and cooling steps are used to erase the thermal history of the samples and detect evaporation of small molecules trapped in the samples. Data analyses for determining $T_{\mathrm{g}}$ values were carried out using the last heating cycle thermogram. Results are presented in Figure $\$ 4$ of the Supporting Information.

\section{Thermogravimetric analysis (TGA)}

Thermogravimetric analyses on samples P2EHA-1 to -4 were performed using a TA Instruments Discovery TGA. Samples (5-15 mg) were weighted into tared platinum TGA pans and heated to $900{ }^{\circ} \mathrm{C}$ at $10{ }^{\circ} \mathrm{C} \mathrm{min}^{-1}$ under a flow of $\mathrm{N}_{2}$. Samples P2EHA-5 to -10 (5-15 $\mathrm{mg}$ ) were analysed on a Texas instrument Q-600 thermogravimetric analyser. Again, TGA was carried out under nitrogen atmosphere with the temperature increased from room temperature to $900{ }^{\circ} \mathrm{C}$ at $10{ }^{\circ} \mathrm{C} \mathrm{min}^{-1}$. The degradation temperature was determined from a significant mass loss step in the mass versus temperature curve. In some cases a smaller mass loss step was observed at around $100{ }^{\circ} \mathrm{C}$ due to loss of hydration water (previously absorbed by the sample). Results are presented in Figure S5 to S7 of the Supporting Information. 


\subsection{NMR Spectroscopy}

\section{Solution-state NMR spectroscopy}

${ }^{1} \mathrm{H}$ NMR spectra of P2EHAs synthesized at $25^{\circ} \mathrm{C}$ and $4{ }^{\circ} \mathrm{C}$ were acquired in $\mathrm{CDCl}_{3}$ at $25^{\circ} \mathrm{C}$ on an Agilent $400 \mathrm{MHz}$ NMR with Varian 7600-AS auto-sampler, equipped with a oneNMR probe and variable temperature capabilities, operating at a Larmor frequency of 399.84 $\mathrm{MHz}$. A few mg of P2EHA were dissolved in a few $\mathrm{mL}$ of $\mathrm{CDCl}_{3}$. ${ }^{1} \mathrm{H} \mathrm{NMR}$ spectra were acquired with 16,384 data points, 8 scans, $16 \mathrm{ppm}$ spectral width $(6410.3 \mathrm{~Hz}), 40 \mathrm{~s}$ relaxation delay, $2.556 \mathrm{~s}$ acquisition time and $90^{\circ}$ flip angle. As the peaks were not assigned using solution-state NMR, the scale was not calibrated for these spectra, which were used only for the measurement of conversion.

Prior to this an inversion recovery experiment was carried out to measure the longitudinal relaxation time, $T_{1}$, of the residual monomer signals as well as the $\mathrm{CH}$ and $\mathrm{CH}_{2}$ main-chain signals. Results are given in the Supporting Information (Table S11).

\section{Melt-state NMR spectroscopy}

${ }^{13} \mathrm{C}$ magic angle spinning (MAS) NMR experiments on samples P2EHA-1 to -6 were carried out on a Bruker Avance 850 MNR spectrometer operating at a Larmor frequency of 213.8 $\mathrm{MHz}$ for ${ }^{13} \mathrm{C}$ using a double resonance ${ }^{1} \mathrm{H}_{-}{ }^{13} \mathrm{C}$ MAS $4 \mathrm{~mm}$ probe. The chemical shift was referenced to TMS at $0 \mathrm{ppm}$. The spinning frequency was set to $10000 \mathrm{~Hz}$ to reduce the intensities of the first two spinning side bands.

${ }^{13} \mathrm{C}$ magic angle spinning (MAS) NMR experiments of samples P2EHA-7 and -8 were carried out on a Bruker Avance 400 MNR spectrometer operating at a Larmor frequency of 100.5 $\mathrm{MHz}$ for ${ }^{13} \mathrm{C}$ using a KelF (PTCFE) liquid insert inside a $\mathrm{ZrO}_{2}$ rotor with KelF caps. The spinning frequency was set to $6 \mathrm{kHz}$ to reduce the number of spinning side bands.

Quantitative ${ }^{13} \mathrm{C}$ NMR spectra were recorded at $50{ }^{\circ} \mathrm{C}$ with single-pulse excitation under magic-angle spinning (SPE-MAS) using $1.4 \mu \mathrm{s}$ at high field and $4.3 \mu \mathrm{s}$ at low field, corresponding to $25^{\circ}$ pulse (Ernst angle), and a 10 s relaxation delay, accumulating 20000 to 40000 transients corresponding to two to five days of experimental time, with inverse gated spinal 64 dipolar decoupling ( $12.5 \mathrm{kHz}$ during $82 \mathrm{~ms}$ acquisition time). Recording 
spectra with 10 and $20 \mathrm{~s}$ relaxation delays led to the same relative peak intensities for the $C_{q}$ and backbone signals, while some peaks were not relaxed properly for shorter delays.

Full spectra of CTA-containing P2EHA and of non-CTA-containing P2EHA, as well as the signal assignments, are in the Supporting Information (Schemes S1 to S5, Figures S8, S13 and S14, and Table S14).

The degree of branching, $D B$, was quantified in percentage of monomer units by comparing the integrals, $I$, of $\mathrm{C}_{\mathrm{q}}$ at $48 \mathrm{ppm}$ and of the main chain $\mathrm{CH}$ at $40-43 \mathrm{ppm}$ as follows:

$$
D B(\%)=\frac{100 \cdot I\left(C_{q}\right)}{I\left(C_{q}\right)+I(C H)}
$$

As ${ }^{13} \mathrm{C}$ NMR spectra showed that even after 5 days of drying in a Schlenk line, a nonnegligible amount of residual monomer was still present, it was not possible to use the signals of the carbons in the ester side groups to quantify $D B$.

$D B$ was also calculated by comparing the integrals of the quaternary carbon to that of the carboxylic ester group, as follows:

$$
D B(\%)=\frac{100 \cdot I\left(C_{q}\right)}{I(C O O R)}
$$

The degree of $\beta$-scission, $D \beta S$, was also calculated in percentage of monomer units by comparing the integrals of the quaternary unsaturated carbon produced by $\beta$-scission at 138 ppm ( $\left.\mathrm{Cbs}^{\prime}\right)$ and of the main chain $\mathrm{CH}$ at $40-43$ ppm:

$$
D \beta S(\%)=\frac{100 \cdot I\left(C b s^{\prime}\right)}{I\left(C b s^{\prime}\right)+I(C H)}
$$

The quaternary unsaturated carbon Cbs' was chosen rather than the secondary unsaturated carbon $\mathrm{Cbs}$ as the latter gives a lower signal due to potential spinning side bands.

The DMfit software package ${ }^{[35]}$ was used to analyse and fit the data. It allows reconstitution of the NMR spectra by fitting the different signals as Gaussian and Lorentzian functions. The integration and relative standard deviations (RSD) of $D B$ and $D \beta S$ (in percent of $D B$ and $D \beta S$ values) were calculated with this software, based on the error on the amplitude of each fitted signal (for further details, see below Table S15). The values of $D B$ and $D \beta S$ as well as an example of a fit are given in the Supporting Information (Table S15 and Figure S9). 


\section{Results and Discussion}

\subsection{Polymerizations}

In experiments with AIBN, final conversion was higher in the absence of CTA (see Table 1). This is consistent with termination being faster in the presence of DDM, which is a well known consequence of chain-length-dependent termination. ${ }^{[36,37]}$ On the other hand, CTAcontaining-P2EHAs synthesized with a redox initiator have a higher conversion than the nonCTA ones, opposite to what is expected. This could be caused by a higher rate of initiation for redox systems in the presence of mercaptans, which can be oxidized to form disulfide, thus additionally stimulating peroxide reduction to generate radicals. We simply wish to note this as an observation - i.e., higher polymerization rate for redox-initiated systems in the presence of DDM - rather than investigate it in detail.

\subsection{Thermal Analyses}

By DSC it was found that $T_{\mathrm{g}}$ values for our P2EHA samples were between -90 and $-70{ }^{\circ} \mathrm{C}$. This establishes that $50^{\circ} \mathrm{C}$ is an acceptable temperature for melt-state NMR measurement, which should be done around $T_{\mathrm{g}}+150^{\circ} \mathrm{C}$. By TGA it was shown that our polymer samples do not degrade until the temperature is above $300^{\circ} \mathrm{C}$. This confirms that the polymer still has its integrity in NMR experiments at $50^{\circ} \mathrm{C}$.

\subsection{End Groups by ${ }^{13} \mathrm{C}$ NMR}

Number-average degree of polymerization, $D P_{n}$, was estimated by integration of ${ }^{13} \mathrm{C} N \mathrm{NM}$ signals of main-chain $\mathrm{CH}$ and terminal $\mathrm{CH}_{2}$. Where values could be obtained (i.e., chain length less than 100), they are reported in Table 1. They show that addition of CTA reduces $D P_{n}$, as it should, and that increasing temperature also reduces $D P_{n}$, as also would be expected (on the basis of increasing rate of initiation).

\subsection{End Groups by ESI-MS}

All P2EHA samples were analysed by ESI-MS in order to deduce the end-groups. Figures 1 and 2 show partial ESI-MS spectra of P2EHA synthesized at 140, 100, 65, 25 and $4{ }^{\circ} \mathrm{C}$. 

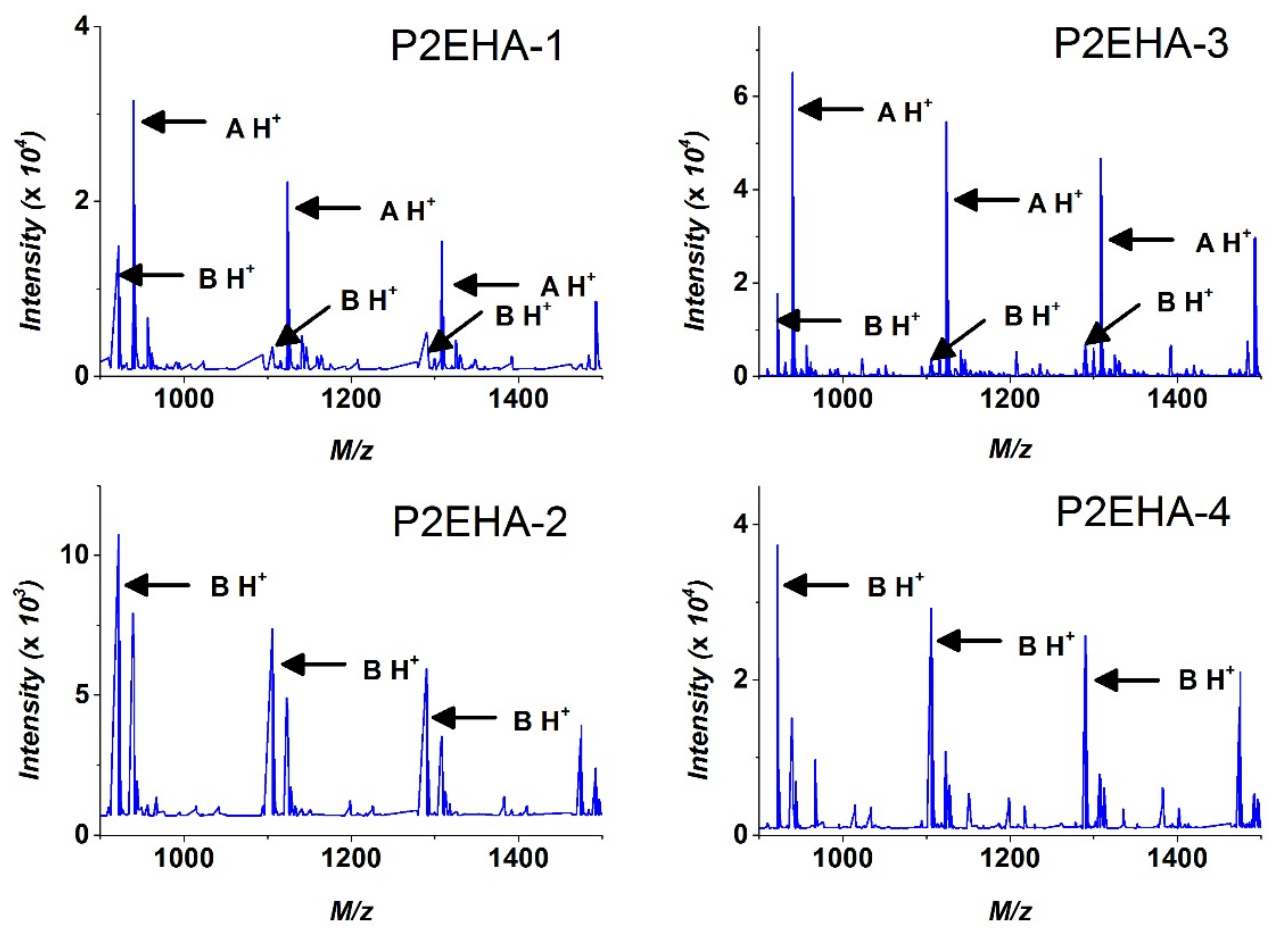

Figure 1: Partial ESI-MS spectra: P2EHA-1 and -2 were synthesized at $140{ }^{\circ} \mathrm{C}$ in presence and absence, respectively, of CTA; analogous for P2EHA-3 and -4 but at $100{ }^{\circ} \mathrm{C}$. Letters refer to species in Schemes 2 and 3.
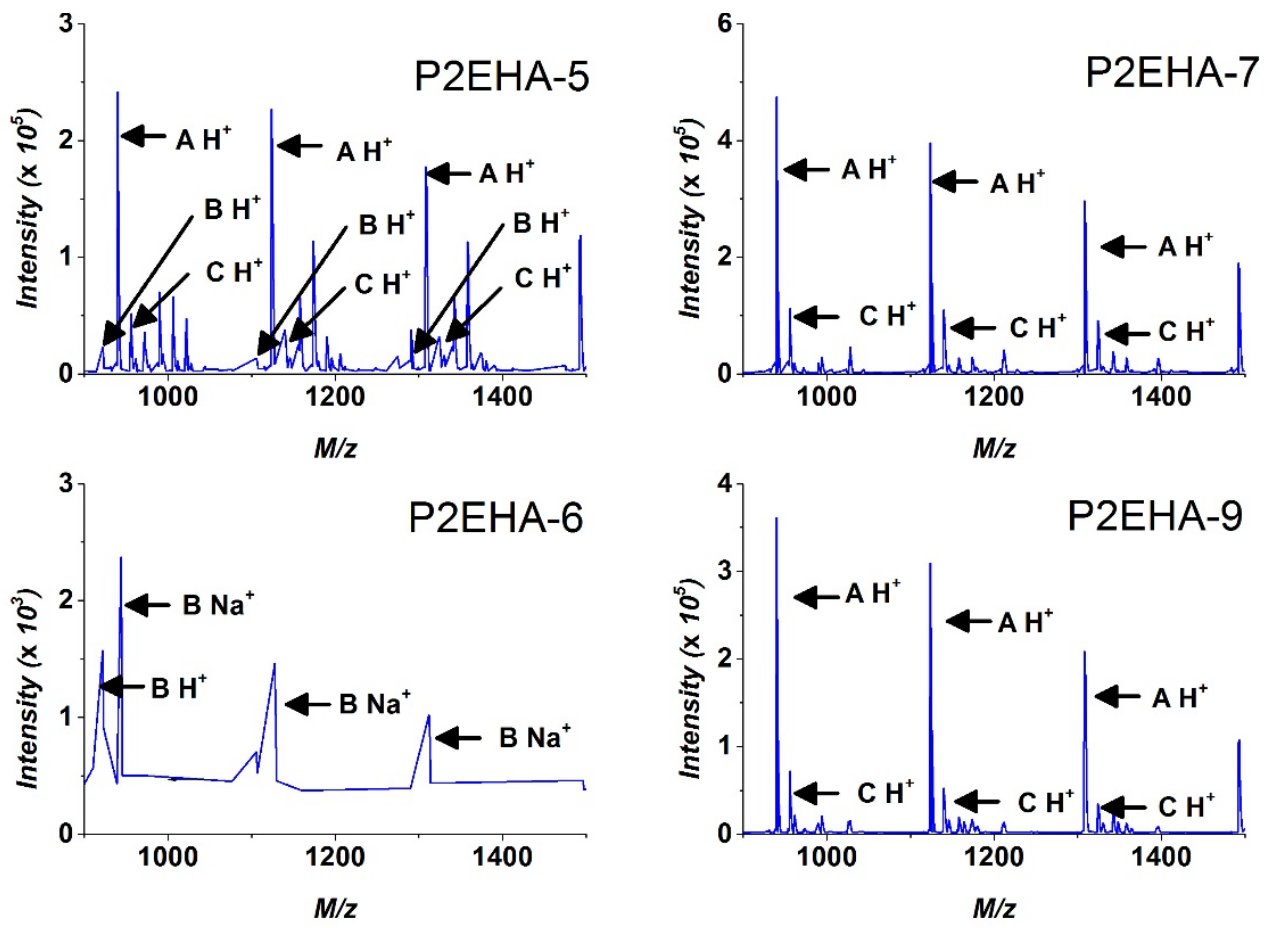

Figure 2: Partial ESI-MS spectra: P2EHA-5 and -6 were synthesized at $65^{\circ} \mathrm{C}$ in presence and absence, respectively, of CTA; P2EHA-7 and -9 were synthesized at 25 and $4{ }^{\circ} \mathrm{C}$, respectively, in presence of CTA. Letters refer to species in Schemes 2 and 3. 
Note that P2EHA-8 and -10 were analysed by ESI-MS but only noisy spectra were obtained (Figure S15). These are the samples from the lowest two temperatures without CTA. Thus the polymer chains were relatively long, making ionization difficult. Furthermore, these syntheses used $\mathrm{Fe}^{2+}$ for initiation, and the samples were solid. Under such circumstances it is believed that iron aggregates are incorporated with the polymer, which makes ESI-MS analysis difficult. On the other hand, samples P2EHA-7 and -9 (made with CTA) were oily, with the residual iron on the bottom of the flask, and thus it did not affect the ESI-MS process.

A striking conclusion from Figures 1 and 2 is the strong presence of polymer with neither cyanoisopropyl $\left(\left(\mathrm{CH}_{3}\right)_{2}(\mathrm{CN}) \mathrm{C}-\right.$, from AIBN) nor $\mathrm{C}_{12} \mathrm{H}_{25} \mathrm{~S}-$ (from DDM) as endgroups. Such polymer can only arise from $\beta$-scission. Thus it is established that $\beta$-scission occurred to a significant extent in our syntheses. We denote polymer formed from $\beta$-scission with a ' $\mathrm{B}$ '. Figures 1 and 2 also show polymer with $\mathrm{C}_{12} \mathrm{H}_{25} \mathrm{~S}-$ and $-\mathrm{H}$ as endgroups. These species we denote with an ' $A$ '; they arise from polymer started (hence $\mathrm{C}_{12} \mathrm{H}_{25} \mathrm{~S}-$ ) and terminated $(-\mathrm{H})$ by transfer to CTA. They are present in samples P2EHA-1, $-3,-5,-7$ and -9 , all the syntheses with CTA, thereby evidencing the importance of transfer to CTA in these systems, even right down to $4{ }^{\circ} \mathrm{C}$. This is consistent with the finding of Hutchinson et al. ${ }^{[34]}$ that the tansfer constant for DDM has a low activation energy. Finally, polymer with $\mathrm{C}_{12} \mathrm{H}_{25} \mathrm{~S}-$ at both ends is found in systems with CTA at and below $65^{\circ} \mathrm{C}$. Such polymer can only arise from combination - hence the ' $C$ ' label - of two macroradicals started by chain transfer. All this labelling is presented visually in the top half of Scheme 2.

A<smiles>[R]OC(=O)C(CC)CC(C)(C)SCCCCCC</smiles>

B<smiles>[R]OC(=O)CC(CC(C)C)C(=O)O[R]</smiles>

B2

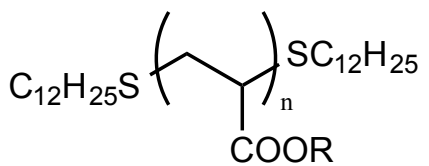

COOR

$$
\mathrm{R}=\mathrm{CH}_{2} \mathrm{CH}(\mathrm{Et}) \mathrm{Bu}
$$

Scheme 2: Structure of P2EHA species detected by ESI-MS (see text). 

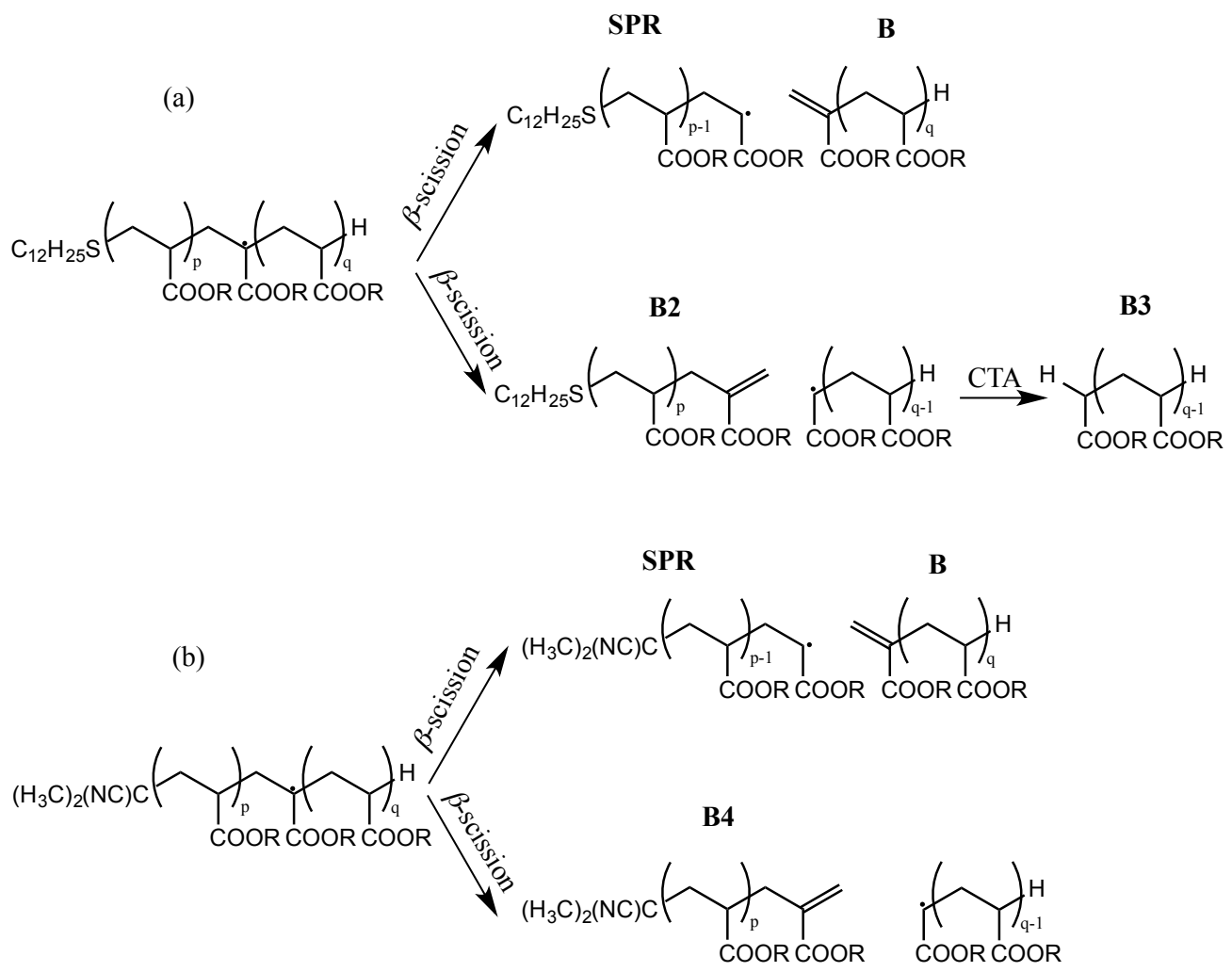

Scheme 3: The different $\beta$-scission products obtained (a) in the presence of CTA, and (b) in the absence of CTA. This scheme is adapted from Koo et al. ${ }^{[26]}$

Although $\beta$-scission is a relatively simple reaction, it ultimately gives rise to a multitude of products, as shown in Scheme 3. This is because an MCR from a thiol-generated polymer can split into either an $\mathrm{H}$-ended or $\mathrm{C}_{12} \mathrm{H}_{25} \mathrm{~S}$-ended radical, as shown in the top half of Scheme 2. Furthermore, there is also the possibility of chains started from AIBN undergoing all these reactions, as shown in the bottom half of Scheme 3. As it turns out, in this work we only detect products from thiol-generated polymer, viz. B, B2 and B3, as summarized in the bottom half of Scheme 2, and as signified in Figures 1, 2 and 3. Note that it is necessary to go to high resolution (e.g. Figure 3) in order to see species B2 and B3.

The other matter to deal with is the nature of the adduct ion in ESI-MS. Predominantly it is $\mathrm{H}^{+}$in this work, as indicated in the figures $\left(\mathrm{A} \mathrm{H}^{+}, \mathrm{B} \mathrm{H}^{+}\right.$, etc.). There are also many minor peaks. These we could always assign to the species identified above but either with different adduct ions $\left(\mathrm{NH}_{4}^{+}, \mathrm{Na}^{+}, n \mathrm{H}_{2} \mathrm{O} \mathrm{H}^{+}, \mathrm{CH}_{3}-\mathrm{CH}_{2}-\mathrm{NH}_{2} \mathrm{H}^{+},{ }^{[38]} \mathrm{CH}_{3} \mathrm{OH} \mathrm{H}{ }^{+}, \mathrm{CH}_{3} \mathrm{OH} \mathrm{H} \mathrm{OH}^{+},\left(\mathrm{CH}_{3} \mathrm{CN}\right)_{2}\right.$ $\mathrm{H}^{+}$) or two adduct ions. We therefore believe that only polymers $\mathrm{A}, \mathrm{B}, \mathrm{B} 2, \mathrm{~B} 3$ and $\mathrm{C}$ were obtained in this work. Tables S2 to S9 in the Supporting Information detail the different 
adducts and compare their observed $\mathrm{m} / \mathrm{z}$ with theoretical values, as calculated with the mMass software (version 3.1.0). ${ }^{[39]}$

$\beta$-scission is detected in P2EHA synthesized at all temperatures. This does not correspond to what was observed previously by NMR spectroscopy, and $\beta$-scission was not expected below $80{ }^{\circ} \mathrm{C}{ }^{[40]} \beta$-scission was not observed in P2EHA synthesized in solution at $60{ }^{\circ} \mathrm{C}^{[4]}$ and in emulsion at $75^{\circ} \mathrm{C}^{[5]}$ but it was observed at $140{ }^{\circ} \mathrm{C}$ in bulk ${ }^{[41]}$ and solution. ${ }^{[11]}$ However, Koo et al. observed by ESI-MS a significant amount of $\beta$-scission even at $60^{\circ} \mathrm{C}$ for PnBA in both presence and absence of 1-octanethiol. ${ }^{[26]}$ This is likely due to the sensitivity of ESI-MS, which is higher than in NMR spectroscopy. As well as extending the PnBA finding to P2EHA, the presence of species $\mathrm{B}$ in P2EHA made at $25^{\circ} \mathrm{C}$ and $4{ }^{\circ} \mathrm{C}$ is a new discovery in this study. The presence of MCRs in P2EHA made at $25^{\circ} \mathrm{C}$ was detected by EPR spectroscopy ${ }^{[6]}$ and at $-34{ }^{\circ} \mathrm{C}$ by SEC. ${ }^{[29]}$ While this does not corroborate the occurrence of $\beta$-scission at these low temperatures, it at least establishes it as a possibility.

A noticeable result is that polymerization of $2 \mathrm{EHA}$ at elevated temperature (100 and $140{ }^{\circ} \mathrm{C}$ ) predominantly produces pure macromonomer - see the ESI-MS spectra for P2EHA-2 and -4. This is consistent with previous findings for PnBA. ${ }^{[42]}$ However, when CTA is introduced this situation changes: there is a higher proportion of A species. Again, this is consistent with results in the literature: Junkers et al. found that the presence of a CTA reduces the amount of $\beta$-scission in PnBA. ${ }^{[25]} \mathrm{A}$ simple explanation for this is that the frequency of transfer to CTA exceeds that of $\beta$-scission, which should be (relatively) unaffected by the presence of CTA. There may also be a boost to the level of A species from the so-called patching effect i.e., the bottom reaction in Scheme 1; however this is not essential to explain the fundamental observation.

The other observation about B species is that they diminish as temperature decreases. This is an expected result because it is well known that backbiting has a relatively high activation energy, and thus the MCR fraction decreases as temperature is lowered. We observed that C species - from combination of transfer-started radicals - are evident in samples P2EHA-5, -7 and -9 , being of relatively equal amount to $B$ species at $65{ }^{\circ} \mathrm{C}$ and largely replacing them at the two lower temperatures, consistent with the known low activation energy of acrylate 
termination. ${ }^{[43,44]}$ That said, Figure 3 suggests that $B$ species are still present at 25 and $4{ }^{\circ} \mathrm{C}$, but at very low amount.
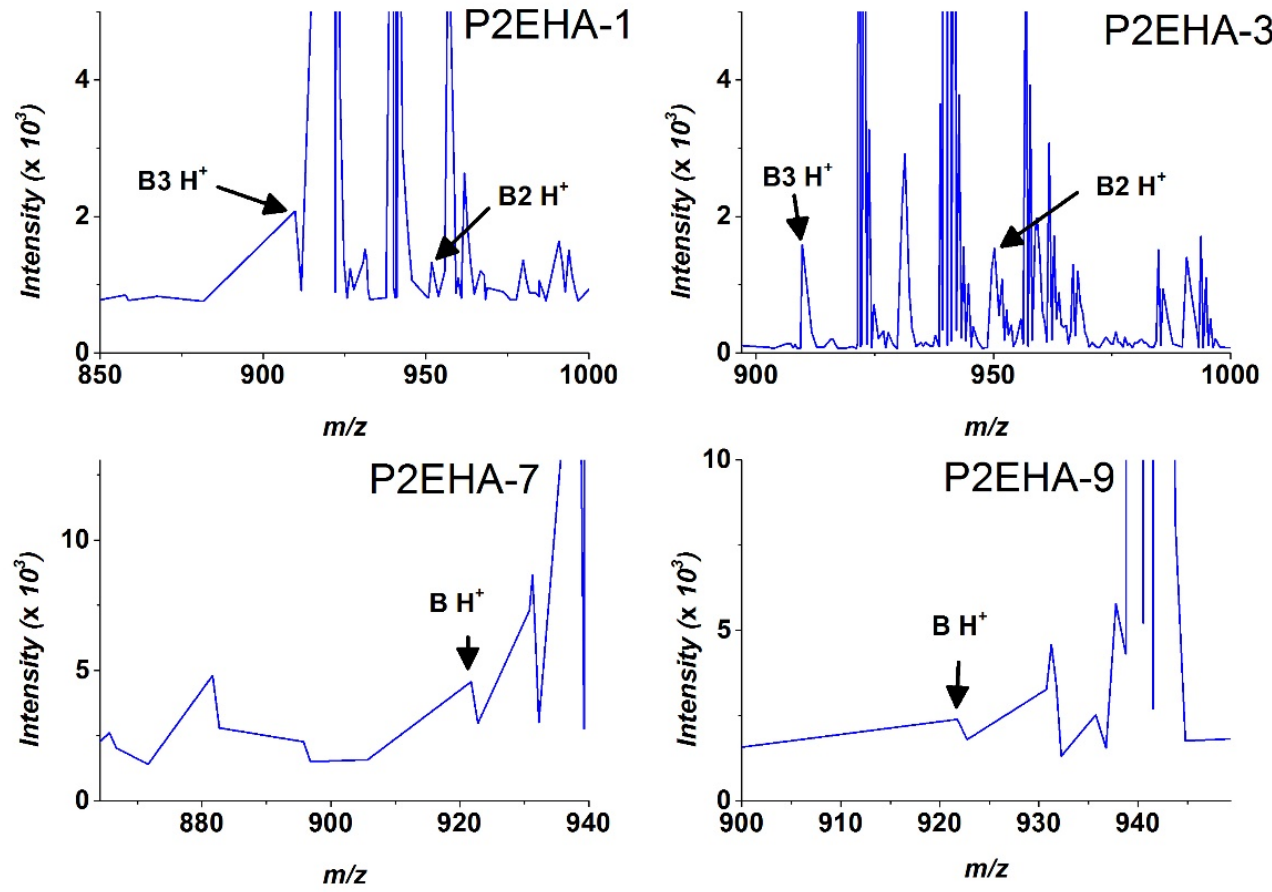

Figure 3: Close-ups of ESI-MS spectra of CTA-containing P2EHAs synthesized at $140{ }^{\circ} \mathrm{C}$ (P2EHA-1), $100{ }^{\circ} \mathrm{C}$ (P2EHA-3), $25^{\circ} \mathrm{C}$ (P2EHA-7) and $4{ }^{\circ} \mathrm{C}$ (P2EHA-9).

Of cource $\mathrm{C}$ species may not form in the absence of CTA. This means that dead chains must form either by $\beta$-scission or by termination of radicals from initiator. As already mentioned, the latter species are not observed in this work. Accordingly, only B species are observed for P2EHA-6 (65 ${ }^{\circ} \mathrm{C}$ without CTA), but their relative amount is very low, because the chainlength distribution is relatively long.

Some further points to note about our ESI-MS results now follow. Species B2 and B3 are observed in the CTA-containing P2EHAs obtained at $140{ }^{\circ} \mathrm{C}$ and $100{ }^{\circ} \mathrm{C}$ but the intensity of their peaks is less than $10 \%$ of the intensity of the peaks of species B. This was also observed in the case of $\mathrm{PnBA}^{[26]}$ and explained by a complex set of equilibria between the scission products and the MCRs, as $\beta$-scission is a reversible reaction. ${ }^{[45]}$ Species B4 is never observed in this study although it was present (in low abundance) in the work of Koo et al. on PnBA. ${ }^{[26]}$ 


\subsection{Average Degree of Branching and Average Degree of $\beta$-scission}

Samples P2EHA-1 to -8 were analysed by ${ }^{13} \mathrm{C}$ melt-state NMR spectroscopy. $D B$ and $D \beta S$ were quantified. P2EHA-9 and -10 were not analysed by ${ }^{13} \mathrm{C}$ NMR spectroscopy as the detection of the quaternary carbon would take over one week on a $400 \mathrm{MHz}$ equipment. Furthermore, as we were not able to measure $D B$ and $D \beta S$ from NMR of our $25{ }^{\circ} \mathrm{C}$ samples (see below), it follows that they would also not be measureable for the samples from $4{ }^{\circ} \mathrm{C}$.

Figures 4 and 5 show portions of ${ }^{13} \mathrm{C}$ NMR spectra of P2EHAs synthesized at $140{ }^{\circ} \mathrm{C}$ with and without CTA. Quantitative spectra with good sensitivity were obtained with $10 \mathrm{~s}$ repetition delay at $50{ }^{\circ} \mathrm{C}$, which is about $120-130{ }^{\circ} \mathrm{C}$ above $T_{\mathrm{g}}$. The conditions for observing the signal of $\mathrm{C}_{\mathrm{q}}$ in different poly(alkyl acrylate)s are summarised in Table S13 of the Supporting Information.

(a)

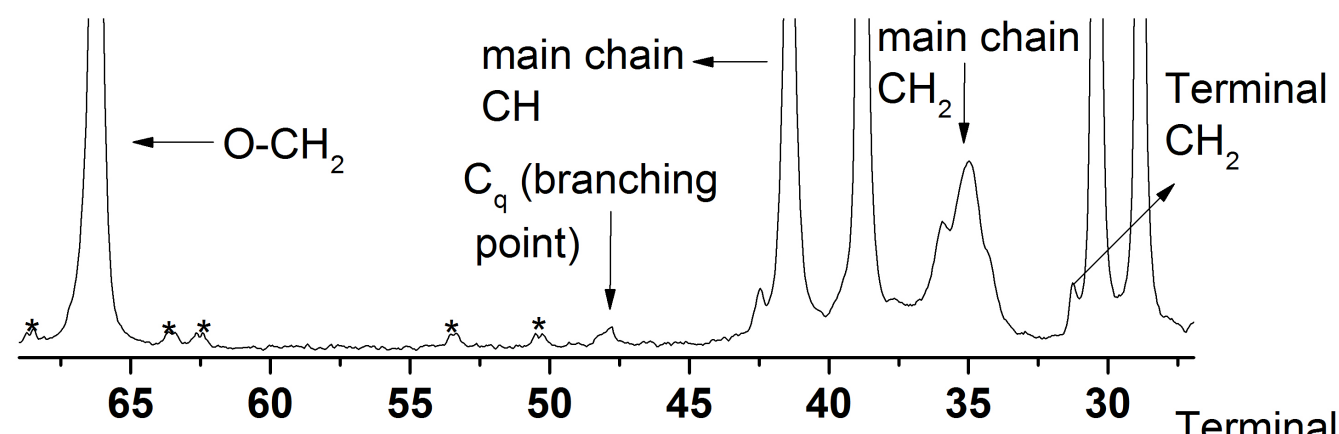

(b)

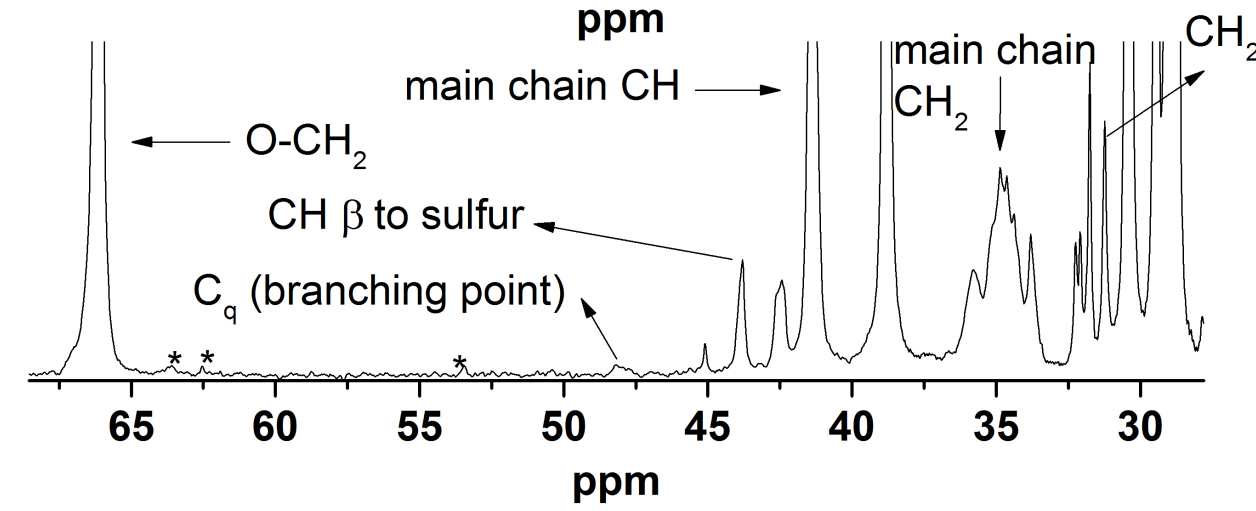

Figure 4: Partial ${ }^{13} \mathrm{C}$ melt-state NMR spectra (27 - $70 \mathrm{ppm}$ ) at $50{ }^{\circ} \mathrm{C}$ of P2EHA synthesized at $140{ }^{\circ} \mathrm{C}(\mathrm{a})$ without and (b) with $\mathrm{CTA}$, where * denotes signals from side spinning bands. 


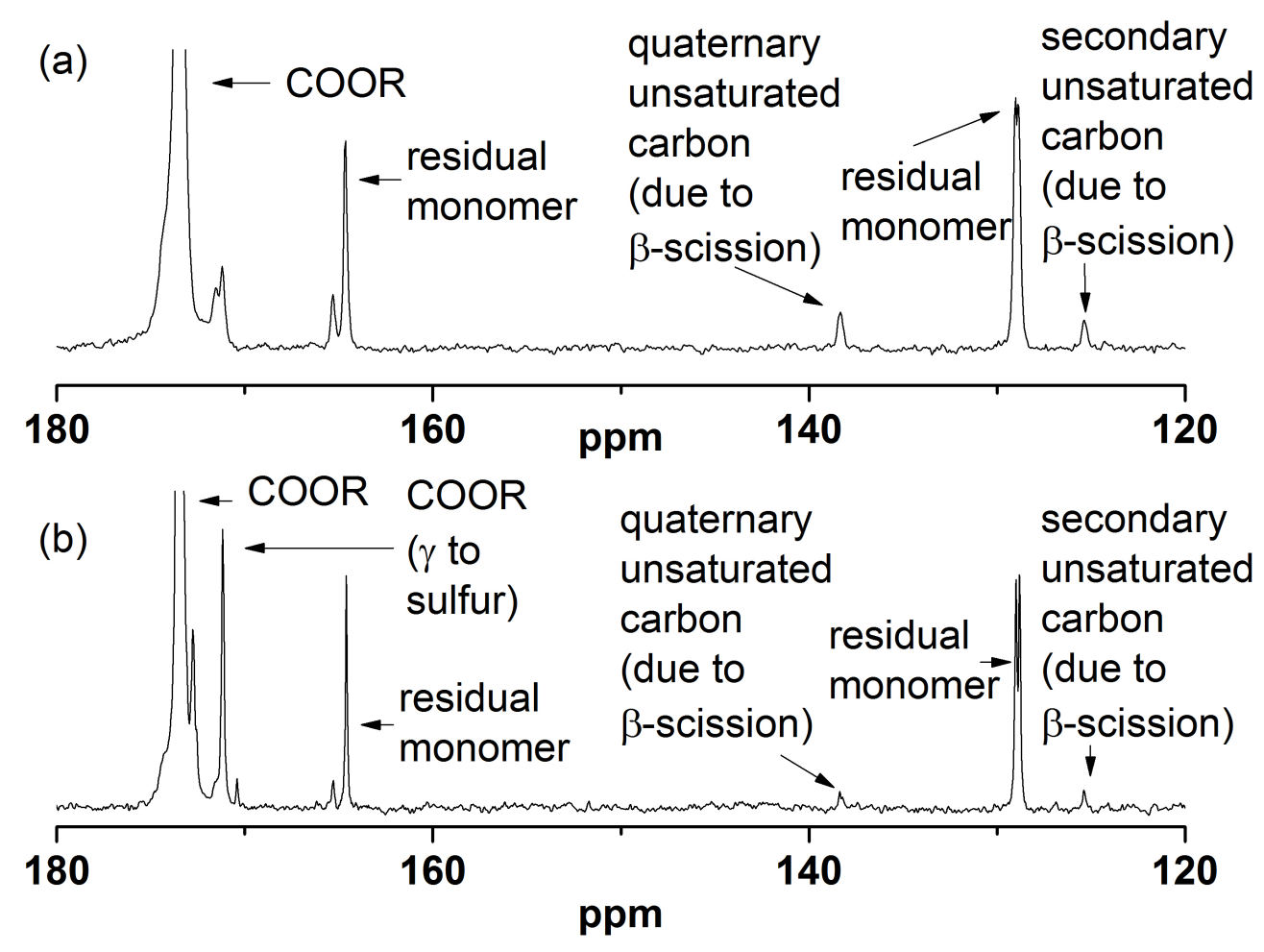

Figure 5: Partial ${ }^{13} \mathrm{C}$ melt-state NMR spectra $(120-180 \mathrm{ppm})$ at $50{ }^{\circ} \mathrm{C}$ of P2EHA synthesized at $140{ }^{\circ} \mathrm{C}(\mathrm{a})$ without and (b) with CTA.

The different values obtained for $D B$ (with Equations (1) and (2)) are similar in magnitude if the residual standard deviation $(R S D)$ is considered. Results are presented in Figure 6. At $25{ }^{\circ} \mathrm{C}$, neither branching nor $\beta$-scission products were observed by ${ }^{13} \mathrm{C}$ NMR spectroscopy. Consequently, the P2EHAs obtained at $4{ }^{\circ} \mathrm{C}$ were not analysed by melt-state NMR spectroscopy. This confirms the findings of Sato et al. ${ }^{[6]}$ but is different to the results of Castignolles et al. ${ }^{[29]}$ and Couvreur et al. ${ }^{[30]}$ who both divined the presence of LCB in P2EHA synthesized by PLP in bulk at $-34{ }^{\circ} \mathrm{C}$ and low conversion. This was done using SEC, analysing the shape of the chromatogram. As a tool for probing kinetics there can be no doubt that ${ }^{13} \mathrm{C}$ NMR is far more sensitive than SEC, however It is possible that SEC can detect the rheological effects of LCB (e.g. one such branch per long chain) even when it is negligible as a kinetic event. 


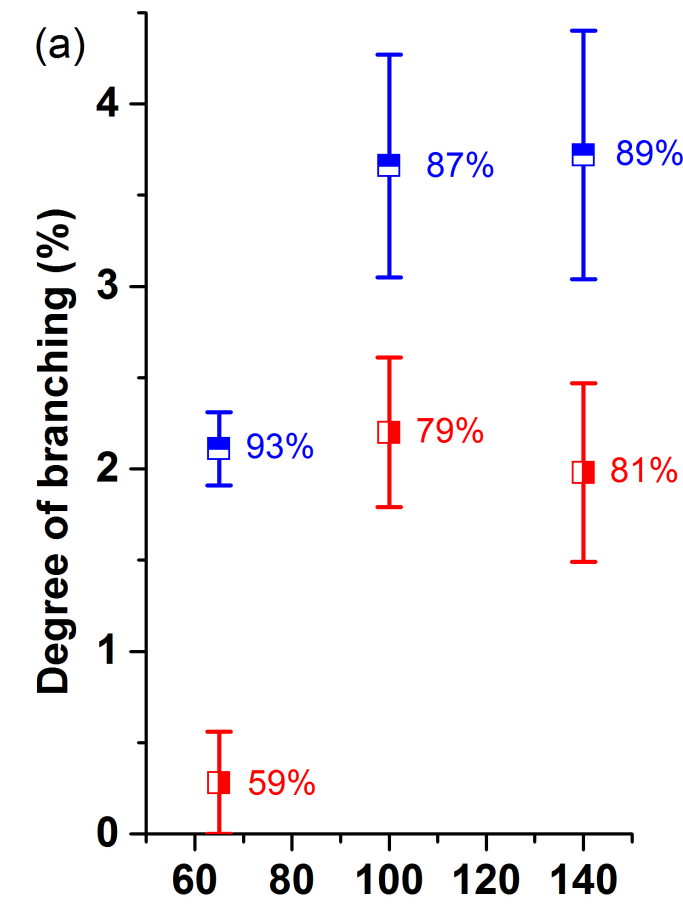

Temperature $\left({ }^{\circ} \mathrm{C}\right)$

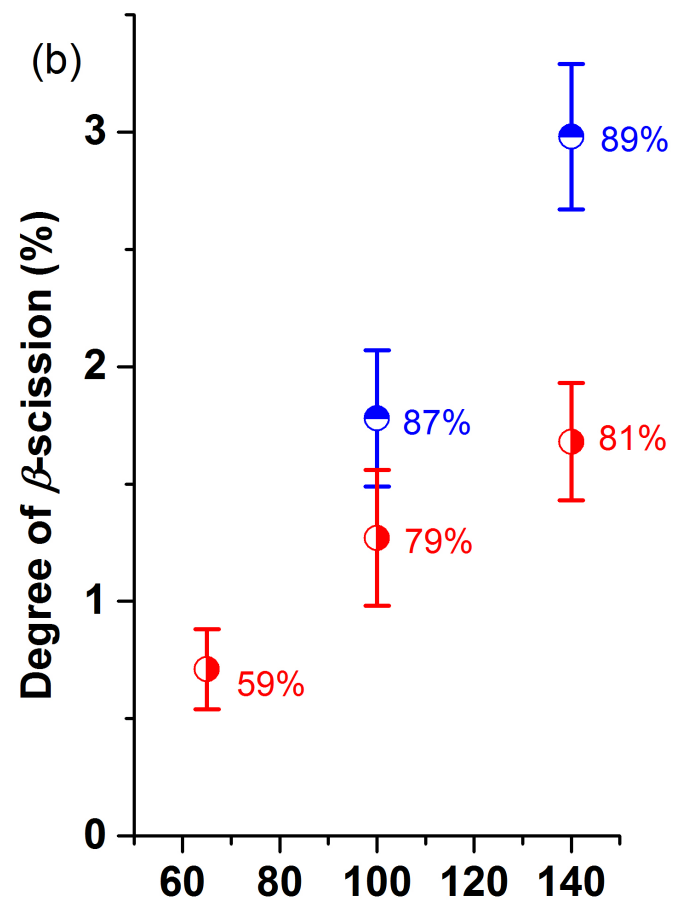

Temperature $\left({ }^{\circ} \mathrm{C}\right)$

Figure 6: (a) Average degree of branching (DB; squares; from Equation 1) and (b) average degree of $\beta$-scission ( $D \beta S$; circles; from Equation 3 ) of CTA-containing (red points with vertical division) and non-CTA-containing (blue, horizontal) P2EHAs synthesized in bulk at different temperatures. The monomer conversion from the synthesis is given as a written value next to each point.

Firstly, Figure $6(\mathrm{~b})$ is consistent with the ESI-MS results obtained by Junkers et al. ${ }^{[25]}$ and by Koo et al.: ${ }^{[26]}$ for both these previous investigations of $n \mathrm{BA}$ and the present study of 2EHA it is found that the amount of $\beta$-scission is reduced by the presence of a CTA and increases with temperature. The most obvious explanation for the lower $D \beta S$ in the presence of CTA is the patching effect - some MCRs react with thiol before they have a chance to undergo $\beta$ scission or propagation. In this context we note but cannot rigorously explain that we were unable to measure $D \beta S$ for the sample made at $65{ }^{\circ} \mathrm{C}$ but without CTA (i.e., the absent blue point in Figure $6(b))$. Further confounding this mystery is that we did observe $\beta$-scission product in the ESI-MS of P2EHA-6 (see above). That said, it was only observed with very low intensity, whereas B species in P2EHA-5 were present in higher intensity - this could be relevant for an explanation. 
Secondly, in Figure 6(a) it is observed that $D B$ is considerably reduced by the presence of CTA and increases with temperature up to $100{ }^{\circ} \mathrm{C}$ before remaining the same at $140{ }^{\circ} \mathrm{C}$. The reduction of $D B$ with addition of CTA is by now well known, having already been observed for $\mathrm{PnBA}{ }^{[7,8,25,26]}$ and by ourselves with $\mathrm{PAA}^{[9]}$ Again, the most likely reason is the occurrence of a "patching effect", i.e., a transfer of hydrogen atom between DDM and an MCR. Other contributing factors are also possible. These include: (1) Reduction of the amount of backbiting as, in the presence of CTA, the lifetime of an SPR is shorter; ${ }^{[8]}$ (2) Due to chain-length-dependent propagation, ${ }^{[46]}$ shorter chains - as formed in the presence of CTA - must have a lower $D B$, as the average time between propagation events is lower. (3) When the polymerization temperature is between $65^{\circ} \mathrm{C}$ and $140{ }^{\circ} \mathrm{C}$, the conversion is higher for non-CTA-containing P2EHA. It is known that DB increases with conversion, and has been observed experimentally in the case of $\mathrm{P} 2 \mathrm{EHA}^{[4]}$ and by simulation in the case of PAA. ${ }^{[19]}$ This is simply an effect of lower monomer concentration and therefore lower frequency of propagation (cf. backbiting, which is a unimolecular process); (4) Another possible explanation is an unintended temperature increase, as the fast rate of polymerization of alkyl acrylates can give rise to an exotherm, particularly in bulk polymerization. In the absence of a CTA, chains are longer and so viscosity is higher, meaning that heat is more difficult to remove. If there is an exotherm, then $D B$ would increase. In this context it may seem strange that $D B$ does not continue to rise to $140{ }^{\circ} \mathrm{C}$. However this is simply explained by $\beta$-scission becoming predominant, meaning the effect of an increasing MCR fraction is not immediately reflected in $D B$. It will be shown below that our data does in fact evidence that the backbiting rate coefficient increases from 100 to 140 ${ }^{\circ} \mathrm{C}$.

It is worthwhile to compare the results obtained in this study with ones from the literature. This is done in Figure 7. Firstly, in Figure 7(a) we have gathered $D B$ results from polymer made with CTA and at a similar temperature, viz. $60-70{ }^{\circ} \mathrm{C}$. This temperature is chosen because it is high enough to give measurable $D B$ but low enough that $\beta$-scission plays only a minor role. It is clear that our $65{ }^{\circ} \mathrm{C}$ value for $D B$ is consistent with those from the literature. It is also clear that there is a decrease of $D B$ with initial monomer concentration (noting that whereas our data point is from bulk polymerizaiton, all the literature values are from 
experiments in solution). For conditions of constant monomer concentration, $[M]$, it is well known that $D B \sim[\mathrm{M}]^{-1} \cdot{ }^{[19,47]}$ The data of Figure $7(\mathrm{a})$ shows this trend, which provides a vote of confidence in our data.

In contrast to Figure $7(a)$, Figure $7(b)$ examines the effect of temperature. The results obtained in this study are compared with those from Gaborieau et al. ${ }^{[7]}$ for PnBA. In both studies the polymerizations were carried out in bulk and with the same initiator at approximately the same concentration (about $40 \%$ different). Furthermore, the same ratio of CTA to monomer was used, the only difference in this regard being 1-octanethiol in the previous work versus DDM presently, which should make negligible difference. In summary, conditions in both sets of experiments were almost identical, apart from $n B A$ versus 2EHA. Considering this it must be said that the results of Figure $7(b)$ are in excellent agreement. The only differences are in the no-CTA systems at 100 and $140{ }^{\circ} \mathrm{C}$, and even these are within experimental error to all intents and purposes. In this context it should be noted that in the $\mathrm{P} n \mathrm{BA}$ work there was no measurement of $D \beta S$, so it is possible that the $\mathrm{PnBA} D P$ at $140{ }^{\circ} \mathrm{C}$ somehow includes a contribution from $\beta$-scission, and so is an overestimate. Then again, it has been observed that $\mathrm{P} 2 \mathrm{EHA}$ is more affected by $\beta$-scission than PnBA. ${ }^{[6]}$

Having said this above, in the literature it has been found that the P2EHA is more branched than PnBA when synthesized in solvent at $60{ }^{\circ} \mathrm{C}^{[6]}$ and $70{ }^{\circ} \mathrm{C}^{[4]}$ This was explained by a higher accessibility of the tertiary $\mathrm{CH}$-bond in P2EHA, which would lead to the formation of more MCRs. ${ }^{[4]}$ Kattner and Buback have recently confirmed that as the pendant alkyl group of an acrylate increases in size, the fraction of MCRs increases, ${ }^{[22]}$ which - in the absence of $\beta$-scission - would mean higher $D B$. This is left as an open issue, although it is noted that there are only 3 points in the PnBA study and that this was a method-establishment work. ${ }^{[7]}$ 
(a)

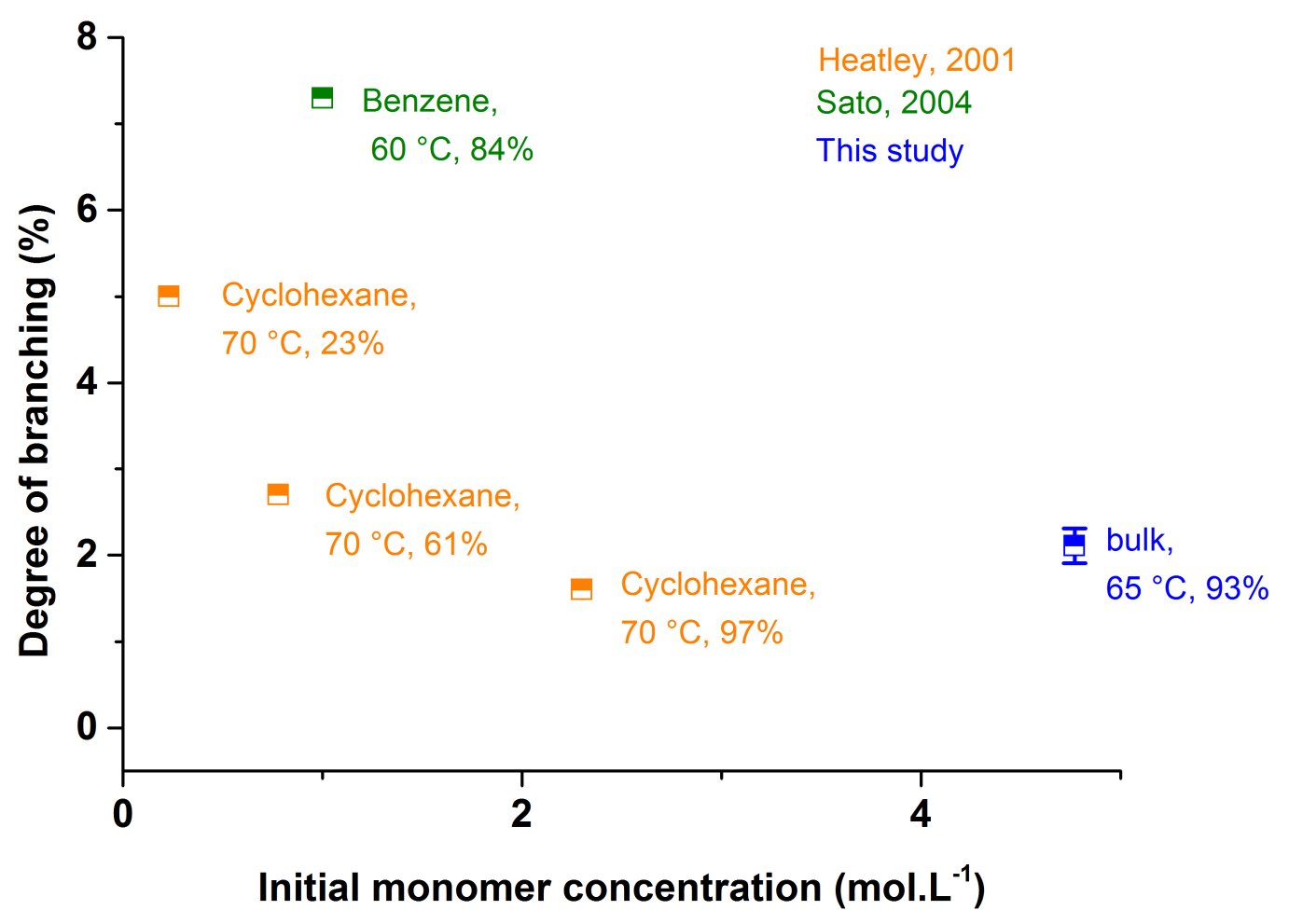

(b)

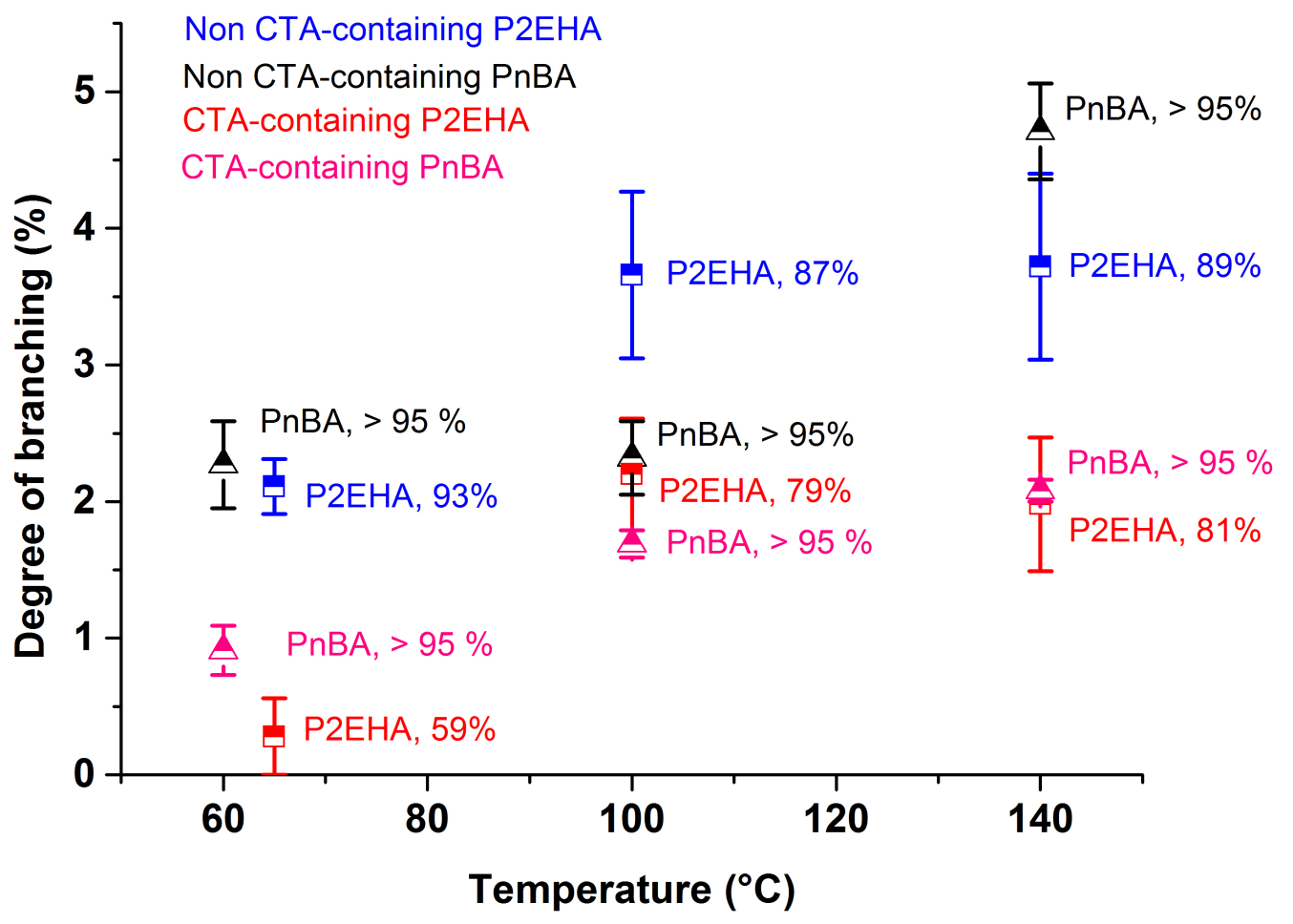

Figure 7: Comparisons of degree of branching, $D B$, obtained in this and previous studies. (a) Effect of initial monomer concentration at similar temperature for P2EHA, where literature data is from Heatley et al. ${ }^{[4]}$ and Sato et al. ${ }^{[6]}$ (b) Effect of temperature and CTA for P2EHA (this study) and PnBA (Gaborieau et al. ${ }^{[7]}$ ) in otherwise similar conditions (bulk, same CTA/monomer and initiator/monomer). In both cases the final conversion is given. 


\subsection{Rate Coefficients}

Historically it has been assumed in determining $k_{\mathrm{bb}} / k_{\mathrm{p}}$ from $D B$ values that [M] stays approximately constant throughout an experiment. In a lot of experiments this has not been the case, including the present work, in which bulk experiments were carried out to high conversion and then the polymer isolated for analysis. This means that during an experiment the monomer concentrating is decreasing, and so the balance between SPR propagation, of frequency $k_{\mathrm{p}}[\mathrm{M}]$, and backbiting, $k_{\mathrm{bb}}$, is constantly changing, and thus the instantaneous $D B$ is contantly changing; specifically, it will increase as conversion increases, and thus the cumulative $D B$ will also increase. In view of this, Nikitin et al. derived Equation (4) for cumulative $D B,{ }^{[48]}$ as determined in this work:

$$
D B(\%)=\frac{k_{\mathrm{bb}} 100 \ln \left(\frac{[\mathrm{M}]_{0}}{[\mathrm{M}]_{\mathrm{e}}}\right)}{k_{\mathrm{p}}\left([\mathrm{M}]_{0}-[\mathrm{M}]_{\mathrm{e}}\right)}
$$

Here $[\mathrm{M}]_{0}$ and $[\mathrm{M}]_{\mathrm{e}}$ are the monomer concentrations at the start and end, respectively, of a polymerization. This equation assumes negligible loss of MCRs by transfer, $\beta$-scission and termination, i.e., that all MCRs become a branch site. It also assumes negligible occurrence of LCB, i.e., it assumes all branches are formed by backbiting. Our earlier study on PAA was the first to apply this equation to $D B$ data. ${ }^{[9]}$

There is a complication in applying Equation (4) in the present work, which is that clearly it cannot be assumed that $\beta$-scission occurs to a negligible extent. To overcome this, we assume that all MCRs either propagate to give a branch site or undergo $\beta$-scission to give a terminal double bond. In this situation it would seem to us that Equation (4) can be simply adapted as follows:

$$
D B(\%)+D \beta S(\%)=\frac{k_{\mathrm{bb}} 100 \ln \left(\frac{[\mathrm{M}]_{0}}{[\mathrm{M}]_{\mathrm{e}}}\right)}{k_{\mathrm{p}}\left([\mathrm{M}]_{0}-[\mathrm{M}]_{\mathrm{e}}\right)}
$$

This equation has all the assumptions of Equation (4) apart from that regarding $\beta$-sicssion. However, it does additionally assume that there is negligible consumption of macronomoner by propagation. It is felt that these assumptions are reasonable. Obviously the use of either Equation (4) or (5) assumes that accurate values of $[M]_{e}$ have been obtained. In our study we were not able to prove that the residual monomer signals in ${ }^{13} \mathrm{C}$ 
NMR spectroscopy are quantitative. For this reason our final conversions may be overestimated.

Equation (5) enables determination of $k_{\mathrm{bb}} / k_{\mathrm{p}}$ for our bulk E2HA data. The Arrhenius plot of the resulting values is Figure S12. For no-CTA data the Arrhenius fit is

$$
k_{\mathrm{bb}} / k_{\mathrm{p}}\left(\mathrm{mol} \mathrm{L}{ }^{-1}\right)=5.5 \times 10^{1} e^{-\frac{20.6 \times 10^{3}}{R T}}\left(65^{\circ} \mathrm{C}<\theta<140^{\circ} \mathrm{C}\right)
$$

Here $T$ is temperature in $\mathrm{K}$ and $\theta$ in ${ }^{\circ} \mathrm{C}$. Strictly speaking Equation (5) should not be used for polymer made with CTA, as it assumes that MCRs do not undergo transfer to CTA. Nevertheless we still analyzed our CTA data in this way, obtaining

$$
k_{\mathrm{bb}} / k_{\mathrm{p}}\left(\mathrm{mol} \mathrm{L}^{-1}\right)=9.6 \times 10^{0} e^{-\frac{15.7 \times 10^{3}}{R T}}\left(65^{\circ} \mathrm{C}<\theta<140^{\circ} \mathrm{C}\right)
$$

We stress that Equation (6b) does not actually give true values of $k_{\mathrm{bb}} / k_{\mathrm{p}}$ for systems with CTA. Rather, it gives values that incorporate the patching reaction, which of course acts to lower the apparent rate of backbiting. Nevertheless we present Equation (6b), as it may be used to estimate $D B+D \beta S$ for systems with the present concentration of DDM, which was approximately $10 \mathrm{~mol} \%$ relative to monomer.

To obtain individual values of $k_{\mathrm{bb}}$, the value of $k_{\mathrm{p}}$ is needed. This was calculated according to Equation (7), ${ }^{[31]}$ which was obtained from PLP-SEC experiments over the indicated temperature range:

$$
k_{\mathrm{p}}\left(\mathrm{L} \mathrm{mol}^{-1} \mathrm{~s}^{-1}\right)=9.1 \times 10^{6} e^{-\frac{1901}{T}}\left(10^{\circ} \mathrm{C}<\theta<60^{\circ} \mathrm{C}\right)
$$

Only the no-CTA points were treated this way, as the aim is to obtain the true value of $k_{\mathrm{bb}}$, not an apparent value due to the occurrence of patching. Our $k_{\mathrm{bb}}$ results are presented in Figure 8 while the ensuing Arrhenius parameters - activation energy, $E_{a}$, and preexponential factor, $A$ - are given in Table 2, with errors given in Table S16. Table 2 also includes values from a variety of literature studies. 


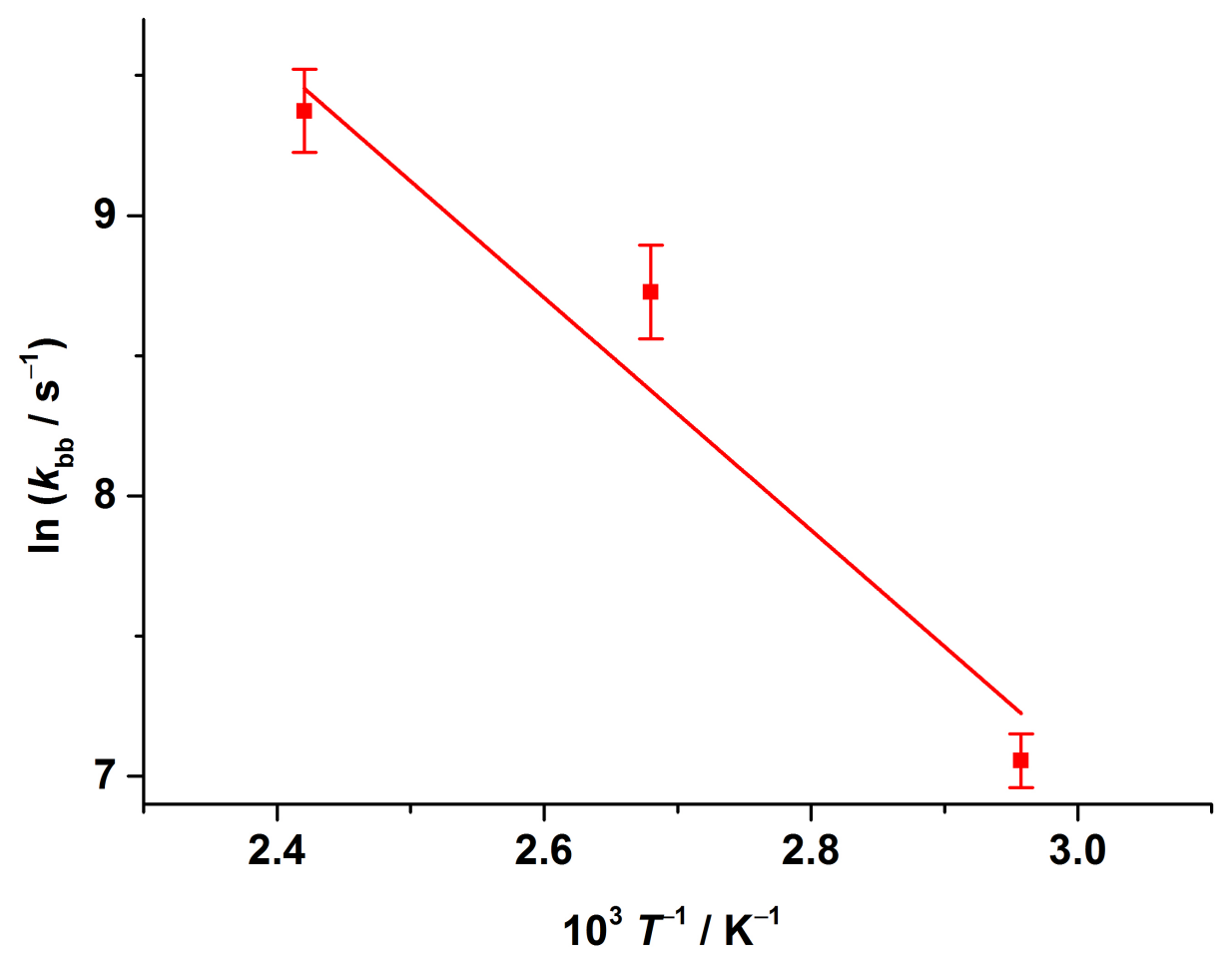

Figure 8: Arrhenius plot of backbiting rate coefficient, $k_{\mathrm{bb}}$, of $2 \mathrm{EHA}$, as obtained from experiments without CTA.

Table 2: Frequency factor, $A$, and activation energy, $E_{a}$, of backbiting rate coefficient, $k_{b b}$, for different acrylates. The measurement temperature range, method and solvent are indicated.

\begin{tabular}{|c|c|c|c|c|c|c|c|}
\hline Acrylate & $\begin{array}{c}A \\
\left(10^{8} \mathrm{~s}^{-1}\right)\end{array}$ & $\begin{array}{c}E_{\mathrm{a}} \\
\left(\mathrm{kJ} \mathrm{mol}^{-1}\right)\end{array}$ & $\begin{array}{c}\theta \text { range } \\
\left({ }^{\circ} \mathrm{C}\right)\end{array}$ & Reference & Method & Solvent & $\begin{array}{c}k_{\mathrm{bb}} \text { at } 50^{\circ} \mathrm{C} \\
\left(10^{2} \mathrm{~s}^{-1}\right)^{\dagger}\end{array}$ \\
\hline dodecyl (DA) & 2.1 & 35.2 & $0-60$ & [22] & SP-PLP-EPR & toluene & 4.3 \\
\hline $2 \mathrm{EHA}$ & 4.4 & 35.9 & $65-140$ & \multirow{2}{*}{$\begin{array}{l}\text { this study } \\
{[49]}\end{array}$} & NMR & \multirow{2}{*}{$\begin{array}{c}\text { none } \\
\text { heptane* }\end{array}$} & 6.9 \\
\hline$n \mathrm{BA}$ & 0.35 & 29.3 & $-16-60$ & & NMR & & 6.4 \\
\hline$n \mathrm{BA}$ & 320 & 52.3 & $60-140$ & [18] & NMR & $p$-xylene* & 1.1 \\
\hline$n \mathrm{BA}$ & 0.48 & 31.7 & $-10-40$ & [50] & PLP-SEC & none & 3.6 \\
\hline$n B A$ & 1.6 & 34.7 & $0-60$ & [51] & SP-PLP-EPR & toluene & 3.9 \\
\hline methyl (MA) & 1.5 & 33.2 & $0-60$ & [22] & SP-PLP-EPR & toluene & 6.4 \\
\hline$A A^{\#}$ & 5.1 & 36.4 & $5-40$ & [52] & SP-PLP-EPR & water & 6.7 \\
\hline$A A$ & 9.9 & 38.0 & $20-75$ & [19] & NMR & water & 7.1 \\
\hline$A A$ & 29 & 42.1 & $50-90$ & [9] & NMR & water/THF & 4.5 \\
\hline
\end{tabular}

${ }^{\dagger}$ Calculated from given Arrhenius parameters.

\# Determined from $k_{\mathrm{bb}}$ values tabulated in Supporting Information. ${ }^{[52]}$

* Some experiments carried out in bulk, some in the given solvent. 
It is clear from Table 2 that all but one of the previous determinations of $k_{\mathrm{bb}}$ have been at lower temperatures than the present work. Further, the previous $n B A$ study ${ }^{[18]}$ over a similar temperature range stands out in Table 2 for having inexplicably high Arrhenius parameters. For these reasons no other data is presented in Figure 8 - it would just be to compare our results with a set of extrapolations. Instead, in Figure 9 - which will shortly be discussed - we compare the extrapolated fit of our results with the fits of some other results over the temperature range of their measurement.

Values of $k_{\mathrm{bb}}$ at $50{ }^{\circ} \mathrm{C}$ for each Arrhenius fit are given in Table 2, and it is clear there is good agreement in most cases. However an obvious conculsion to draw from Table 2 is that it is difficult to obtain Arrhenius parameters for $k_{\mathrm{bb}}$ with high accuracy. In this context it is evident that the values from the present work sit very comfortably within historical averages. Indeed, of the five determinations of $E_{\mathrm{a}}\left(k_{\mathrm{bb}}\right)$ by $\mathrm{NMR}$, the present one looks to be the most accurate.

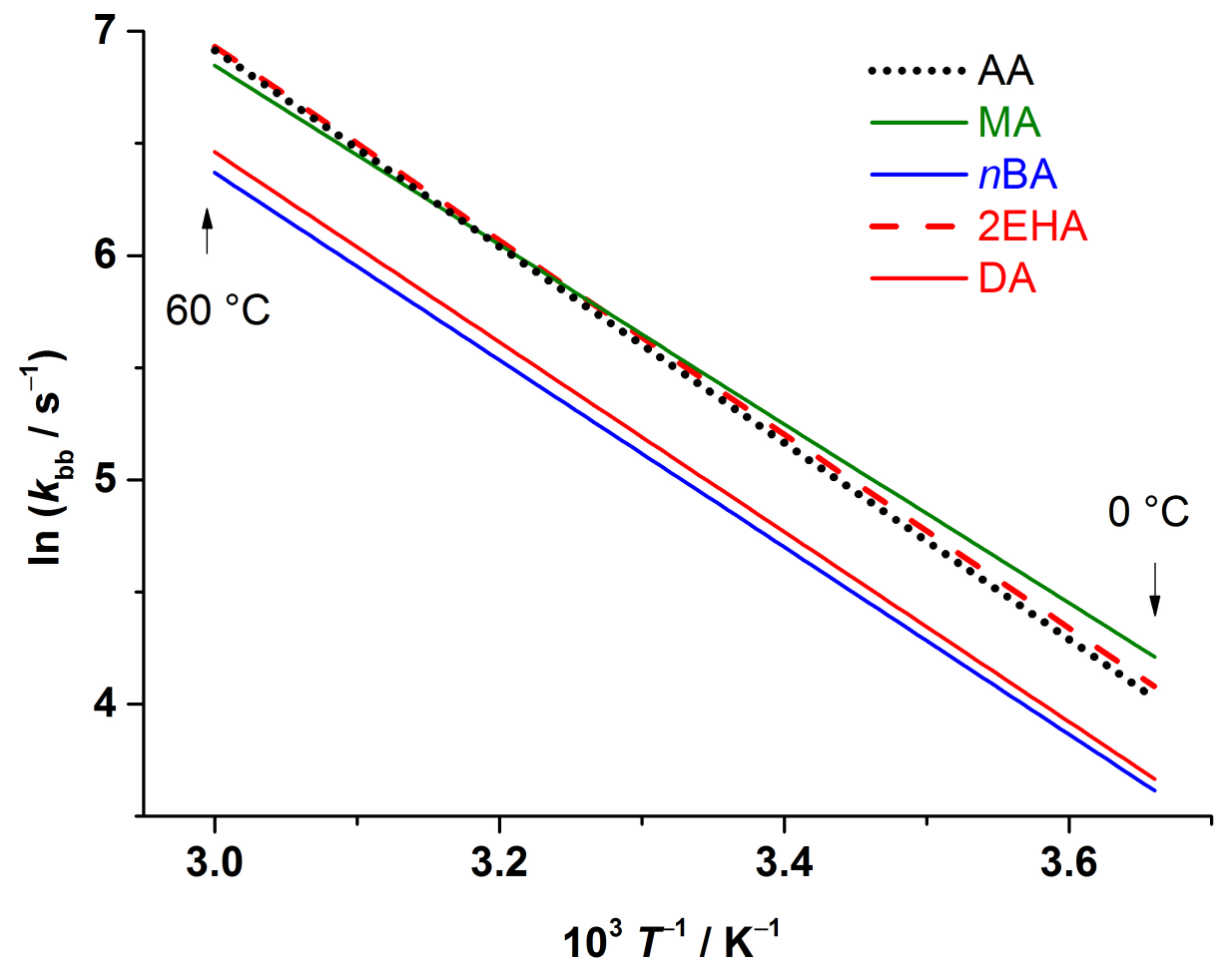

Figure 9: Arrhenius fits of backbiting rate coefficients, $k_{b b}$, for acrylic acid ${ }^{[52]}$ (AA), methyl acrylate $^{[22]}, n$-butyl acrylate ${ }^{[51]}$ (nBA), 2EHA (present work) and dodecyl acrylate ${ }^{[22]}$ (DA). All of these literature results were obtained by SP-PLP-EPR, as opposed to the use of NMR in the present work. The temperature range is that from the SP-PLP-EPR studies. 
It is evident from Table 2 that the technique of SP-PLP-EPR delivers $k_{\mathrm{bb}}$ with the highest precision of the four methods so far used, as the four values of $E_{\mathrm{a}}\left(k_{\mathrm{bb}}\right)$ obtained this way are within the relatively small range of $33.2-36.4 \mathrm{~kJ} \mathrm{~mol}^{-1}$. Arguably this is not surprising, as the technique probes the radicals most directly: a single-pulse PLP experiment is carried out within an EPR cavity, meaning that the SPR and MCR concentrations can be monitored as the SPRs created by the laser pulse are converted into MCRs by backbiting. It is very pleasing that our $E_{\mathrm{a}}\left(k_{\mathrm{bb}}\right)$ for 2EHA falls exactly within the narrow range of values found by SP-PLPEPR, whereas values found previously by other techniques for other acrylates are outside it.

Given the above we have plotted in Figure 9 the Arrhenius fits from the four SP-PLP-EPR studies with that from the present work. Previously Kattner and Buback plotted just the MA, $B A$ and DA values. Here we add also their fit for $A A \cdot{ }^{[52]}$ On the basis of these results it seems reasonable to make the tentative conclusion that there is family-type behavior in acrylate $k_{\mathrm{bb}}$, with $E_{\mathrm{a}} \approx 35 \mathrm{~kJ} \mathrm{~mol}^{-1}$ and $A$ weakly decreasing as the alkyl side group increases in size (as is reflected in the $50{ }^{\circ} \mathrm{C}$ values of Table 2), at least for solution polymerization in toluene. We note that this is similar to acrylate $e^{[53]}$ and methacrylate ${ }^{[54]} k_{p}$, except that there the variation of $A$ goes in the opposite direction in bulk: $E_{\mathrm{a}}$ (of $k_{\mathrm{p}}$ ) is constant but $A$ increases as the alkyl side group becomes larger. That said, Kattner and Buback have found that the rate coefficient for MCR propagation, $k_{\mathrm{p}}{ }^{\mathrm{t}}$, shows the opposite trend in toluene solution polymerization, i.e., significantly decreasing $A$ (with constant $E_{\mathrm{a}}$ ) as the alkyl side group becomes larger. ${ }^{[22]}$ Furthermore, they noted that this is in line with (SPR) $k_{\mathrm{p}}$ under the same circumstances. ${ }^{[55]}$ Figure 9 is uncannily consistent with $k_{b b}$ having this same complexity, i.e., $k$ decreasing with alkyl group size in toluene but increasing in bulk (our 2EHA result). Whatever, decreasing $k_{\mathrm{p}}{ }^{\mathrm{t}}$ combined with decreasing [M] would seem to be the primary cause of MCR fraction increasing as acrylates become larger. Whether there is any significant variation of $k_{\mathrm{bb}}$ from acrylate to acrylate remains to be seen; in fact Kattner and Buback proposed the one Arrhenius fit for all acrylates. ${ }^{[22]}$ We note that Heatley et al. found higher $D B$ in P2EHA than in PnBA, and they interpreted this as being due to an increase in $A\left(k_{\mathrm{bb}}\right)$ because of P2EHA having greater free volume than PnBA, meaning that the tertiary $\mathrm{CH}$ is more accessible for backbiting. ${ }^{[4]}$ If true this is also consistent with the placement of 2EHA in Figure 9. 
That our Arrhenius fit for $k_{\mathrm{bb}}$ nestles so well amongst the SP-PLP-EPR fits - see Figure 9 - is quite remarkable given all the differences between the experiments: EPR versus NMR, PLP versus steady-state, solution versus bulk, low versus extended conversion, and high versus low temperature. Concerning the last difference, there are two important points to make. The first is that our $k_{\mathrm{bb}}$ were obtained from our $k_{\mathrm{bb}} / k_{\mathrm{p}}$ values using an Arrhenius fit for $k_{\mathrm{p}}$ that was obtained over a much lower temperature range, viz. $10-60{ }^{\circ} \mathrm{C}^{[31]}$ Given that we extrapolate this fit to $140{ }^{\circ} \mathrm{C}$ to obtain $k_{\mathrm{bb}}$, the consistency of these $k_{\mathrm{bb}}$ with literature values is outstanding. In particular, all it would take is for $A\left(k_{\mathrm{p}}\right)$ to be too large by a factor of 2 which is a relatively small error - and then our $A\left(k_{\mathrm{bb}}\right)$ would be smaller by a factor of 2 , placing it perfectly in agreement with the BA and DA data of Figure 9. The second point is to be aware that, because of the high temperature, this is the first occasion in which $\beta$-scission has been taken into account in order to determine $k_{\mathrm{bb}} / k_{\mathrm{p}}$. The flipside of this is that when our $k_{\mathrm{bb}}$ values are used, it must be remembered that these give $D B+D \beta S$, and that $D \beta S$ is only negligible at low temperature, estimated to be around $70^{\circ} \mathrm{C}$ and below for $2 \mathrm{EHA}$.

\section{Conclusion}

For many decades the kinetics of acrylate polymerization were a mystery. Around the turn of the century there emerged definitive proof that branching occurs in the polymerization of $n$-butyl acrylate. ${ }^{[15]}$ This was soon followed by a call to arms from van Herk, ${ }^{[56]}$ who correctly sensed that chain transfer to polymer was at the heart of all the mysteries. Progress has been rapid in the 16 years since then. This work makes another contribution to this progress, and there are several elements that we feel elevate this paper above mere "stamp collecting", i.e., routine repetition of past practices. The first is the exceptionally clear identification of $\beta$-scission products in our ESI-MS analyses of P2EHA made at high temperature. The second is the quantification of the level of $\beta$-scission by ${ }^{13} \mathrm{C} N M R$. The third is that both $\beta$-scission and branching are accounted for in determining $k_{\mathrm{bb}} / k_{\mathrm{p}}$. Important in this process is the use - for only the second time - of an equation from Nikitin et al. ${ }^{[48]}$ that allows for experiments to be carried out over a range of conversion, as opposed to being limited just to low conversions. Finally, the $k_{\mathrm{bb}}$ values that we obtain are the first reported for 2EHA and are in outstanding agreement with the most recent - and 
seemingly most accurate - literature values, ${ }^{[22]}$ ones obtained by a completely different method. For all these reasons we feel confident in recommending our methodology for future work. With more studies like these, the acrylate enigma will be fully transformed into a powerful revelation.

\section{Acknowledgement}

Dr. Patrice Castignolles (Western Sydney University) is acknowledged for the idea of investigating 2EHA. Dr. Marion Gaborieau (Western Sydney University), Dr. Chris Fellows (University of New England) and Prof. Per Zetterlund (University of New South Wales) are thanked for counsel and feedback. We are grateful to Dr. Ghislain David (École Nationale Supèrieure de Chimie de Montpellier) and Prof. Denis Bertin (Université d'Aix-Marseille) for providing useful information regarding polymer synthesis at low temperature. Dr. Matt Polson (University of Canterbury) is thanked for assistance in the lab. CNRS France is acknowledged for financial support and access to the NMR facility at CEMHTI (Orléans). JBL is grateful to the University of Canterbury for a UC Doctoral scholarship and for general research support.

\section{References}

[1] A. B. Lopez, J. C. de la Cal, J. M. Asua, Langmuir 2016, 32, 7459.

[2] M. D. Gower, R. A. Shanks, J. Appl. Polym. Sci. 2004, 93, 2909.

[3] D. J. Haloi, N. K. Singha, J. Polym. Sci., Part A: Polym. Chem. 2011, 49, 1564.

[4] F. Heatley, P. A. Lovell, T. Yamashita, Macromolecules 2001, 34, 7636.

[5] C. Plessis, G. Arzamendi, J. M. Alberdi, M. Agnely, J. R. Leiza, J. M. Asua, Macromolecules 2001, 34, 6138.

[6] E. Sato, T. Emoto, P. B. Zetterlund, B. Yamada, Macromol. Chem. Phys. 2004, 205, 1829.

[7] M. Gaborieau, S. P. S. Koo, P. Castignolles, T. Junkers, C. Barner-Kowollik, Macromolecules 2010, 43, 5492.

[8] N. Ballard, J. C. de la Cal, J. M. Asua, Macromolecules 2015, 48, 987.

[9] J.-B. Lena, A. K. Goroncy, J. J. Thevarajah, A. R. Maniego, G. T. Russell, P. Castignolles, M. Gaborieau, Polymer 2017, 114, 209.

[10] W. Wang, A. N. Nikitin, R. A. Hutchinson, Macromol. Rapid Commun. 2009, 30, 2022.

[11] J. Vandenbergh, T. Junkers, Macromolecules 2013, 46, 3324.

[12] N. Ballard, J. M. Asua, Prog. Polym. Sci. 2018, https://doi.org/10.1016/j.progpolymsci.2017.11.002.

[13] P. M. Wood-Adams, J. M. Dealy, A. W. deGroot, O. D. Redwine, Macromolecules 2000, 33, 7489. 
[14] P. Castignolles, R. Graf, M. Parkinson, M. Wilhelm, M. Gaborieau, Polymer 2009, 50, 2373.

[15] N. M. Ahmad, F. Heatley, P. A. Lovell, Macromolecules 1998, 31, 2822.

[16] B. Wenn, G. Reekmans, P. Adriaensens, T. Junkers, Macromol. Rapid Commun. 2015, 36, 1479.

[17] N. M. Ahmad, B. Charleux, C. Farcet, C. J. Ferguson, S. G. Gaynor, B. S. Hawkett, F. Heatley, B. Klumperman, D. Konkolewicz, P. A. Lovell, K. Matyjaszewski, R. Venkatesh, Macromol. Rapid Commun. 2009, 30, 2002.

[18] S. Hamzehlou, N. Ballard, Y. Reyes, A. Aguirre, J. M. Asua, J. R. Leiza, Polym. Chem. 2016, 7, 2069.

[19] N. F. G. Wittenberg, C. Preusser, H. Kattner, M. Stach, I. Lacík, R. A. Hutchinson, M. Buback, Macromolecular Reaction Engineering 2016, 10, 95.

[20] J. Loiseau, N. Doerr, J. M. Suau, J. B. Egraz, M. F. Llauro, C. Ladaviere, Macromolecules 2003, $36,3066$.

[21] L. Couvreur, C. Lefay, J. Belleney, B. Charleux, O. Guerret, S. Magnet, Macromolecules 2003, 36,8260 .

[22] H. Kattner, M. Buback, Macromolecules 2017, in press.

[23] C. Barner-Kowollik, T. P. Davis, M. H. Stenzel, Polymer 2004, 45, 7791.

[24] M. Buback, G. T. Russell, P. Vana, "Elucidation of Reaction Mechanisms: Conventional Radical Polymerization", in: Mass Spectrometry in Polymer Chemistry, 1st edition, C. BarnerKowollik, J. Falkenhagen, T. Gründling, S. Weidner, Eds., Wiley-VCH Verlag \& Co. KGaA, Weinheim, Germany 2012, p. 319, http://www.wiley.com/WileyCDA/WileyTitle/productCd3527329242.html.

[25] T. Junkers, S. P. S. Koo, T. P. Davis, M. H. Stenzel, C. Barner-Kowollik, Macromolecules 2007, 40, 8906.

[26] S. P. S. Koo, T. Junkers, C. Barner-Kowollik, Macromolecules 2009, 42, 62.

[27] M. Gaborieau, T. J. Causon, Y. Guillaneuf, E. F. Hilder, P. Castignolles, Aust. J. Chem. 2010, 63, 1219.

[28] C. M. Guttman, K. M. Flynn, W. E. Wallace, A. J. Kearsley, Macromolecules 2009, 42, 1695.

[29] P. Castignolles, Macromol. Rapid Commun. 2009, 30, 1995.

[30] L. Couvreur, G. Piteau, P. Castignolles, M. Tonge, B. Coutin, B. Charleux, J. P. Vairon, Macromol. Symp. 2001, 174, 197.

[31] T. Junkers, M. Schneider-Baumann, S. P. S. Koo, P. Castignolles, C. Barner-Kowollik, Macromolecules 2010, 43, 10427.

[32] A. B. Pangborn, M. A. Giardello, R. H. Grubbs, R. K. Rosen, F. J. Timmers, Organometallics 1996, 15, 1518.

[33] J. P. A. Heuts, T. P. Davis, G. T. Russell, Macromolecules 1999, 32, 6019.

[34] R. A. Hutchinson, D. A. Paquet, J. H. McMinn, Macromolecules 1995, 28, 5655.

[35] D. Massiot, F. Fayon, M. Capron, I. King, S. Le Calve, B. Alonso, J. O. Durand, B. Bujoli, Z. H. Gan, G. Hoatson, Magnetic Resonance in Chemistry 2002, 40, 70.

[36] G. B. Smith, G. T. Russell, Macromol. Symp. 2007, 248, 1.

[37] G. B. Smith, G. T. Russell, M. Yin, J. P. A. Heuts, European Polymer Journal 2005, 41, 225.

[38] Z. M. Gu, J. Y. Ma, X. G. Zhao, J. Wu, D. L. Zhang, Rapid Communications in Mass Spectrometry 2006, 20, 2969.

[39] M. Strohalm, "mMass - Open Source Mass Spectrometry Tool", http://www.mmass.org/.

[40] J. Chiefari, J. Jeffery, R. T. A. Mayadunne, G. Moad, E. Rizzardo, S. H. Thang, Macromolecules 1999, 32, 7700.

[41] A. M. Zorn, T. Junkers, C. Barner-Kowollik, Macromol. Rapid Commun. 2009, 30, 2028.

[42] J. Chiefari, J. Jeffrey, R. T. A. Mayadunne, G. Moad, E. Rizzardo, S. H. Thang, Macromolecules 1999, 32, 7700.

[43] S. Beuermann, M. Buback, C. Schmaltz, Industrial \& Engineering Chemistry Research 1999, 38, 3338. 
[44] M. Buback, M. Egorov, A. Feldermann, Macromolecules 2004, 37, 1768.

[45] T. Junkers, C. Barner-Kowollik, J. Polym. Sci., Part A: Polym. Chem. 2008, 46, 7585.

[46] J. P. A. Heuts, G. T. Russell, European Polymer Journal 2006, 42, 3.

[47] C. Plessis, G. Arzamendi, J. R. Leiza, H. A. S. Schoonbrood, D. Charmot, J. M. Asua, Macromolecules 2000, 33, 4.

[48] A. N. Nikitin, R. A. Hutchinson, G. A. Kalfas, J. R. Richards, C. Bruni, Macromol. Theory Simul. 2009, 18, 247.

[49] C. Plessis, G. Arzamendi, J. M. Alberdi, A. M. van Herk, J. R. Leiza, J. M. Asua, Macromol. Rapid Commun. 2003, 24, 173.

[50] A. N. Nikitin, R. A. Hutchinson, M. Buback, P. Hesse, Macromolecules 2007, 40, 8631.

[51] J. Barth, M. Buback, P. Hesse, T. Sergeeva, Macromolecules 2010, 43, 4023.

[52] J. Barth, W. Meiser, M. Buback, Macromolecules 2012, 45, 1339.

[53] C. Barner-Kowollik, S. Beuermann, M. Buback, P. Castignolles, B. Charleux, M. L. Coote, R. A. Hutchinson, T. Junkers, I. Lacik, G. T. Russell, M. Stach, A. M. van Herk, Polym. Chem. 2014, 5, 204.

[54] S. Beuermann, M. Buback, T. P. Davis, R. G. Gilbert, R. A. Hutchinson, A. Kajiwara, B. Klumperman, G. T. Russell, Macromol. Chem. Phys. 2000, 201, 1355.

[55] M. Buback, Macromol. Symp. 2009, 275-276, 90.

[56] A. M. van Herk, Macromol. Rapid Commun. 2001, 22, 687. 